\title{
DEVELOPMENT AND VALIDATION OF A HUMAN KNEE JOINT FINITE ELEMENT MODEL FOR TISSUE STRESS AND STRAIN PREDICTIONS DURING EXERCISE
}

\author{
A Thesis \\ presented to \\ the Faculty of California Polytechnic State University, \\ San Luis Obispo
}

\author{
In Partial Fulfillment \\ of the Requirements for the Degree \\ Master of Science in Mechanical Engineering
}

by

Spencer Wangerin

December 2013 
(C) 2013

Spencer Wangerin

ALL RIGHTS RESERVED 


\section{COMMITTEE MEMBERSHIP}

TITLE:

AUTHOR:

DATE SUBMITTED:

COMMITTEE CHAIR:

COMMITTEE MEMBER:

COMMITTEE MEMBER:
Development and validation of a human knee joint finite element model for tissue stress predictions during exercise

Spencer Wangerin

December 2013
Stephen Klisch, Ph.D.

Professor of Mechanical Engineering

Scott Hazelwood, Ph.D.

Associate Professor of Biomedical Engineering

Andrew Davol, Ph.D.

Professor and Chair of Mechanical Engineering 


\section{ABSTRACT}

Development and validation of a human knee joint finite element model for tissue stress and strain predictions during exercise

Spencer Wangerin

Osteoarthritis $(\mathrm{OA})$ is a degenerative condition of cartilage and is the leading cost of disability in the United States. Motion analysis experiments in combination with knee-joint finite element ( $F E)$ analysis may be used to identify exercises that maintain knee-joint osteochondral $(\mathrm{OC})$ loading at safe levels for patients at high-risk for knee OA, individuals with modest $\mathrm{OC}$ defects, or patients rehabilitating after surgical interventions. Therefore, a detailed total knee-joint FE model was developed by modifying open-source knee-joint geometries in order to predict $\mathrm{OC}$ tissue stress and strain during the stance phase of gait. The model was partially validated for predicting the timing and locations of maximum contact parameters (contact pressure, contact area, and principal GreenLagrangian strain), but over-estimated contact parameters compared with both published in vivo studies and other FE analyses of the stance phase of gait. This suggests that the model geometry and kinematic boundary conditions utilized in this FE model are appropriate, but limitations in the material properties used, as well as potentially the loading boundary conditions represent primary areas for improvement.

Keywords: Osteoarthritis, biomechanics, finite element, human knee-joint, motion capture, articular cartilage, meniscus, ligament, stance phase of gait 


\section{ACKNOWLEDGMENTS}

Thanks to Dr. Stephen Klisch and Dr. Scott Hazelwood for their mentorship and guidance in the completion of this thesis. Also, thanks to Jeff Pyle for his assistance, empathy, and friendship.

Special thanks to Ahmet Erdemir, the Cleveland Clinic, Lerner Research Institute, and the Open Knee development team. Their contributions of opensource knee joint geometry to the SimTK database played a pivotal role in the development of this finite element model.

Finally, thank you to my family and friends for their ongoing encouragement, support, and love.

This project was funded by the Extramural Funding Initiative, Cal Poly Graduate \& Research Programs. 
$\begin{array}{lll}\text { CHAPTER } 1 & \text { INTRODUCTION } & 1\end{array}$

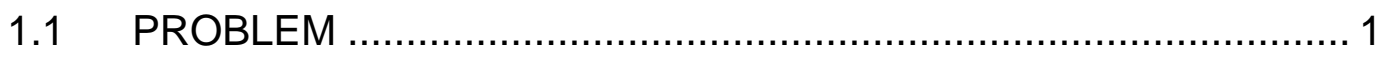

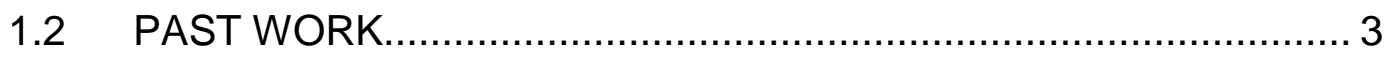

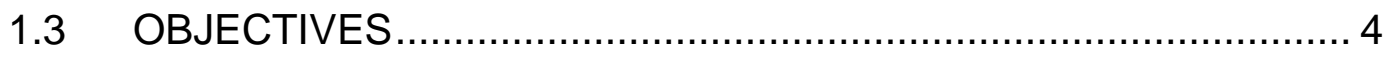

$\begin{array}{lll}\text { CHAPTER } 2 & \text { METHODS } & 6\end{array}$

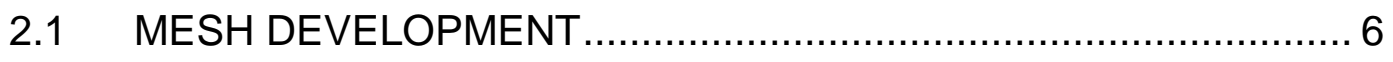

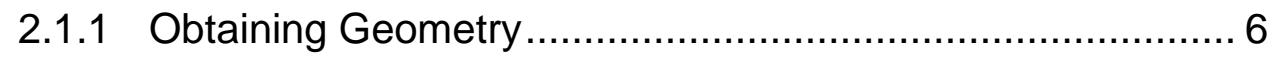

2.1.2 Subject Information ................................................. 7

2.1.3 Solid Modeling …...................................................... 7

2.1.4 Mesh Generation .................................................. 10

$2.2 \quad$ FINITE ELEMENT MODELING ................................................ 14

2.2.1 Material Properties....................................................... 15

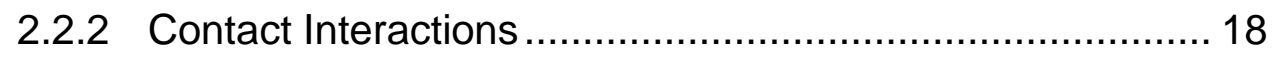

2.2.3 Rigid Body Tie Constraints .......................................... 19

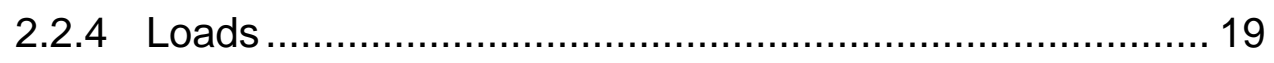




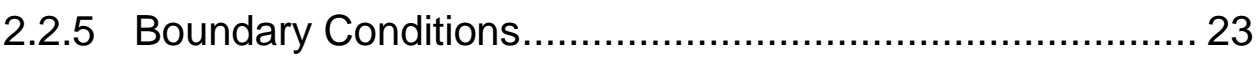

2.2.6 Mesh Convergence …............................................... 25

2.2.7 Damping Stabilization Factor ........................................ 28

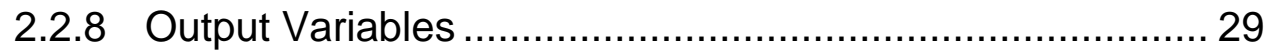

2.2.9 Computer Specifications ............................................. 32

$\begin{array}{lll}\text { CHAPTER } 3 & \text { RESULTS } & 34\end{array}$

$\begin{array}{lll}\text { CHAPTER } 4 & \text { DISCUSSION }\end{array}$

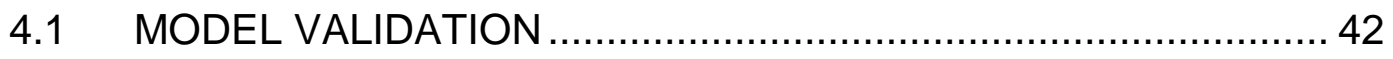

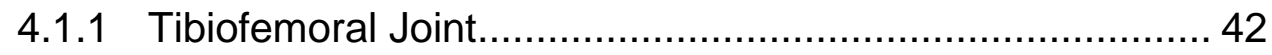

4.1.2 Patellofemoral Joint .................................................. 45

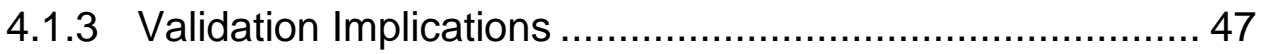

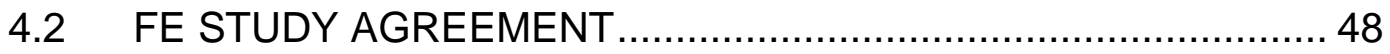

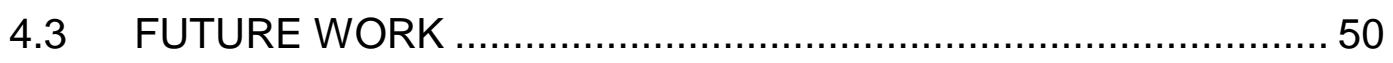

4.3.1 Validation Simulations............................................... 51

4.3.2 Expanded Simulations with OpenSim Muscle Forces ........ 52

4.3.3 Material Properties......................................................... 54

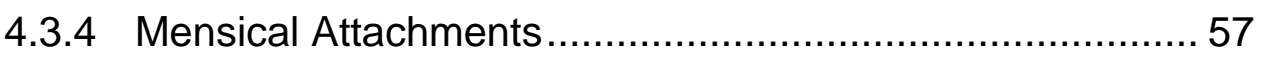

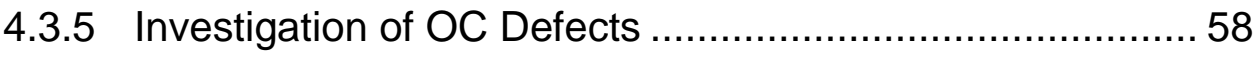

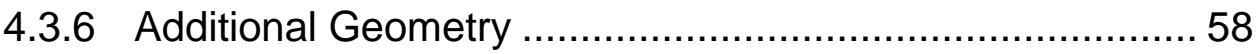

4.3.7 Damping Stabilization Factor Convergence Study ............. 59

4.3.8 Reformulation of Mesh Block Interfaces ......................... 59

4.3.9 Cartilage Matrix Damage and Chondrocyte Apoptosis ...... 61

$\begin{array}{lll}\text { CHAPTER } 5 & \text { CONCLUSION } & 64\end{array}$ 
APPENDIX A UVARM Subroutine for Converting Logarithmic 


\section{LIST OF TABLES}

TABLE PAGE

Table 2.1: Subject information [29] ...................................................... 7

Table 2.2: Description of some TrueGrid commands used in meshing

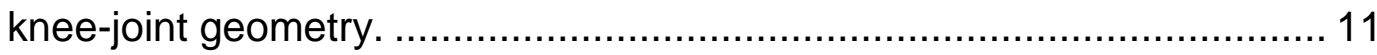

Table 2.3: Summary of material properties applied to each anatomical structure. The properties for all soft tissue structures seek to capture the dynamic response of these tissues for the strain rates and loading times associated with gait. Values from previous FE studies were used for articular cartilage $[35,36]$ and menisci [32, 39], while the ligaments and patellar tendon have properties estimated from experimental tests $[43,44,45]$

Table 2.4: Summary of loads implemented in the FE model for 6 discrete stages of the stance phase of gait.

Table 2.5: Damping stabilization factors used for each loading case and their respective ratios of viscous force (VF) to total forces (TF)

Table 3.1: Maximum contact pressure (MPa) predicted by the FE Model on different aspects of each articular cartilage structure. 35

Table 3.2: Total contact area $\left(\mathrm{mm}^{2}\right)$ predicted by the FE model on different aspect of each articular cartilage structure. 
Table 3.3: Minimum principal Green-Lagrangian strain $(\mathrm{mm} / \mathrm{mm})$ predicted by the FE model on different aspects of each articular cartilage structure. Negative values indicate that the strains are compressive. Strains on each structure are divided by those occurring throughout the entire thickness of articular cartilage geometry (overall) and those occurring on the contact surface with other knee-joint structures (on contact surface) 36

Table 3.4: Maximum principal Green-Lagrangian strain $(\mathrm{mm} / \mathrm{mm})$ predicted by the FE model on different aspects of each articular cartilage structure. Strains on each structure are divided by those occurring throughout the entire thickness of articular cartilage geometry (overall) and those occurring on the contact surface with other knee-joint structures (on contact surface).

Table 3.5: Maximum shear Green-Lagrangian strain $(\mathrm{mm} / \mathrm{mm})$ predicted by the FE model on different aspects of each articular cartilage structure. Strains on each structure are divided by those occurring throughout the entire thickness of articular cartilage geometry (overall) and those occurring on the contact surface with other knee-joint structures (on contact surface).

Table 4.1: Comparison of FE model results with experimental studies; tibiofemoral contact from Liu, et al. [63] and patellofemoral contact in Brechter, et al. [66]. Note: FE model predicted minimum principal (maximum compressive) tibial cartilage strain is compared 
to maximum tibial cartilage deformation $(\mathrm{mm} / \mathrm{mm})$ from Liu, et al. [63]

Table 4.2: Comparison of FE model results with other FE studies: Adouni, et al. [38, 67] and Yang, et al. [68]. 49 


\section{LIST OF FIGURES}

FIGURE

PAGE

Figure 2.1: Solid model assembly of the knee-joint consisting of the distal femur, proximal tibia, patella, articular cartilage (femoral, patellar, and medial and lateral tibial), menisci (medial and lateral), ligaments (anterior cruciate, posterior cruciate, medial collateral, and lateral collateral), and patellar tendon.

Figure 2.2: The modified medial tibial cartilage SolidWorks part file $(A)$ is saved in the .IGES file format and imported into TrueGrid.

Projection curves (B) are defined with numerical designations either automatically or by converting feature edges. Finally, edges and faces of the computational block $(C)$ are projected onto the projection geometry curves and surfaces and divisions in the computational block are refined to produce the final part mesh (D)

Figure 2.3: FE mesh of the knee-joint with individual components labeled. 14

Figure 2.4: Tibia, lateral and medial tibial articular cartilages, and lateral and tibial menisci with menisci boundary conditions labeled. Nodes on the medial faces of the lateral meniscus and the lateral faces of the medial meniscus were constrained in the local z-direction, and nodes along the interior edges of these faces, running inferiorsuperior, were constrained in the local x-direction. 
Figure 2.5: Convergence study results shown for convergence node 1 of the patellar cartilage $(\mathrm{PC})$, convergence node 2 of the lateral tibial cartilage (LTC), convergence node 3 of the PC, and the maximum value on the medial tibial cartilage (MTC)

Figure 3.1: Contact pressure on the anterior and distal aspects of the femoral, posterior patellar, and superior lateral (left) and medial tibial (right) cartilages for different loading conditions during the stance phase of gait $(P X=$ proximal, $D=$ distal, $A=$ anterior, and $\mathrm{PO}=$ posterior direction)

Figure 3.2: Maximum Green-Lagrangian shear strain on the anterior and distal aspects of the femoral, posterior patellar, and superior lateral (left) and medial tibial (right) cartilages for different loading conditions during the stance phase of gait $(P X=$ proximal, $D=$ distal, $\mathrm{A}=$ anterior, and $\mathrm{PO}=$ posterior direction).

Figure 3.3: Maximum principal Green-Lagrangian strain on the anterior and distal aspects of the femoral, posterior patellar, and superior lateral (left) and medial tibial (right) cartilages for different loading conditions during the stance phase of gait $(P X=$ proximal, $D=$ distal, $\mathrm{A}=$ anterior, and $\mathrm{PO}=$ posterior direction).

Figure 4.1: Three-dimensional motion analysis work-flow. (A) A motion capture system records the positions of experimental markers on a subject performing a specific exercise while force plates measure forces and moments. (B) The ID Tool in OpenSim is used to 
calculate equivalent joint contact forces and moments at the kneejoint required to produce the experimentally observed motion. (C) OpenSim's SO Tool is used to obtain individual muscle force vectors and consequently, the resultant joint contact force that can be applied as loads in the future FE model......................................... 53

Figure 4.2: "Free edges" view of meshed parts in Abaqus reveals unintended edges, most likely resulting from an overly fine mesh merging tolerance specified in TrueGrid. 


\section{CHAPTER 1}

\section{INTRODUCTION}

The objectives of this thesis are to develop a total knee-joint finite element (FE) model for predicting articular cartilage and bone (i.e. osteochondral, OC) tissue stress and strain during gait and to validate the model with published data from in vivo studies of gait. The long-term goal of this work is to integrate the knee-joint FE model with a three-dimensional motion analysis system and an inverse dynamic solver in order to study the effects of motion on $\mathrm{OC}$ tissue stress and strain in the knee-joint. Specific, clinically relevant studies may include use of the knee-joint FE model to identify and recommend exercises that prevent OC tissue damage in obese/overweight individuals, slow progression of $\mathrm{OC}$ tissue damage in individuals with minor asymptomatic OC defects being treated conservatively, and facilitate rehabilitation of individuals treated with surgical interventions.

\subsection{PROBLEM}

Articular cartilage is a thin layer of connective tissue located within joints and on the ends of long bones which functions as a low-friction, load bearing material that facilitates normal joint motion [1]. Osteoarthritis (OA) is a degenerative condition of cartilage [2] and is the leading cost of disability in the United States; the total medical expenditure on treatment of $\mathrm{OA}$ and other 
rheumatic diseases was approximately $\$ 81$ billion in 2003 , and affected over 46 million American adults [3]. One risk factor for OA is obesity [4]. Obesity has reached epidemic proportions in the U.S. in recent years; between 2004 and 2008, approximately $33 \%$ of U.S. adults were obese and another $33 \%$ were overweight. These numbers have grown substantially from the obesity rate of $15 \%$ in $1980[5,6]$. Furthermore, the obesity epidemic is very costly in the United States. The total obesity-related medical costs were estimated at $\$ 147$ billion in 2008 [7] and total health costs related to obesity/overweight-related health complications were projected to reach $\$ 900$ billion by 2030 , if current trends continue [8].

Exercise has been identified as a primary prevention and treatment option for obesity [9], as well as part of a physical therapy routine for rehabilitation of knee-joint OA [10]. However, obesity is a risk factor for knee OA partly due to altered and/or increased mechanical loading during exercise [11, 12, 13, 14, 15], possibly in combination with other OA risk factors such as genetic factors, aging, joint deformity/injury, varus-valgus misalignment, bone marrow edema lesions, and hormonal deficiencies [16]. Consequently, exercises for weight control of obese or overweight individuals, rehabilitation, or fitness sustainment for high-risk groups may introduce adverse loading conditions to joints, possibly causing injury to cartilage and bone tissue. Thus, motion analysis experiments in combination with knee-joint finite element analysis (FEA) may be used to identify exercises that maintain knee-joint OC loading at safe levels for patients at high- 
risk for knee $O A$, individuals with modest $O C$ defects, or patients rehabilitating after surgical interventions.

\subsection{PAST WORK}

The relative scarcity of studies on knee-joint loading for OA high-risk groups, and on OC tissue loading during select weight control exercises including gait, elliptical training, and stationary bicycling, serve as barriers to prevention of $\mathrm{OC}$ injury. In vivo knee kinematics and loads (e.g. resultant joint contact and muscle forces and/or joint moments) have been estimated for obese individuals using rigid body dynamics supplemented with force plate measurements during gait $[12,14,17]$. Some studies concluded that knee-joint loading in obese or overweight individuals may be reduced while kinematics are altered during walking $[17,18]$, and due to altered kinematics the load bearing contact region may shift in obese individuals, leading to localized increases in OC tissue stress that may lead to OC injury [11]. Additionally, at least one study examined the effect of varus-valgus misalignment on bone strains in the proximal tibia, although only for patients who had received a total knee replacement surgery [19]. However, an extensive literature search produces no previous FE modeling studies used to predict knee-joint OC tissue stress or strain in obese individuals or other groups at high-risk for OA during gait or other exercises. Thus, the FE model presented in this thesis can be used in future studies with kinematic motion analysis experimental data to address the gap in scientific knowledge in predicting $\mathrm{OC}$ tissue stress and strain in individuals at high-risk for $\mathrm{OA}$. 
For non-impact exercises such as stationary bicycling or elliptical training, knee-joint kinematics and loading have been investigated, although to a much lesser extent than for walking and running. In vivo knee loads (e.g. resultant joint contact and muscle forces) have been estimated using rigid body dynamics supplemented with pedal force measurements during bicycling [20, 21, 22], and elliptical training $[23,24,25]$, and measured in vitro or in vivo using pressure sensitive film (during bicycling) [26] and instrumented prostheses (during bicycling and elliptical training) [27]. An extensive literature search produces only 1 previous FE modeling study, published as a conference paper [28], that predicted knee-joint OC tissue stress for stationary bicycling or elliptical exercises. However, that study did not consider elliptical training and was limited by using a knee FE model that did not include the patella and its associated tissues.

Based on these observations, development of this whole knee-joint FE model will improve both scientific knowledge and clinical practice by better estimating $\mathrm{OC}$ tissue stress and strain during common exercises in high-risk groups for knee-joint OA.

\subsection{OBJECTIVES}

The long-term goal of this project is to use subject-specific, total knee-joint FE models in future studies with a motion analysis system in order to produce subject-specific analysis of walking, elliptical training, and stationary bicycle training for clinically relevant studies aimed at prevention, treatment, and rehabilitation of $\mathrm{OC}$ injuries. The specific objectives of this thesis project are to 
(1) generate a detailed total knee-joint FE model for predicting OC tissue stress and strain during gait and to (2) validate that FE model with published data from in vivo studies of gait. In order to accomplish these objectives, the patella and related structures were added to an open-source knee-joint solid model and then FE modeling studies were performed to estimate articular cartilage stresses during the stance phase of the gait cycle. 


\section{CHAPTER 2}

\section{METHODS}

\subsection{MESH DEVELOPMENT}

The following subsections detail the creation of the whole knee-joint finite element (FE) mesh. This process includes obtaining open-source knee-joint magnetic resonance imaging (MRI) scans and solid models, producing a threedimensional solid model of the total knee-joint geometry, and meshing the total knee-joint model (i.e. discretizing the geometry with finite elements) for importation into a finite element solver.

\subsubsection{OBTAINING GEOMETRY}

The model geometry was adapted from a partially validated threedimensional whole knee-joint model from the Open Knee public domain repository at Simtk.org $[29,30]$, which consists of the distal femur, proximal tibia, patella, articular cartilage (femoral, patellar, medial tibial, and lateral tibial), menisci (medial and lateral), and ligaments (anterior cruciate, posterior cruciate, medial collateral, and lateral collateral), and patellar ligament/tendon (referred to simply as the patellar tendon in subsequent sections of this report). These publicly available resources include rough, digital solid models of component geometries in the .IGES file format, generated from magnetic resonance images 
(MRIs). MRI scans were taken with the knee specimen in the full extension position using a 1.0 Tesla extremity MRI scanner (Orthone, ONI Medical Systems Inc., Wilmington, MA), with 1.5 millimeter slices in three anatomical planes (axial, sagittal, and coronal), at the Biomechanics Laboratory of the Cleveland Clinic [29].

\subsubsection{SUBJECT INFORMATION}

The donor subject used for generating model geometry is female, 70 years old, 5 feet 6 inches tall, approximately 170 pounds, and died of natural causes. Table 2.1 includes a summary of this information. The subject's Body Mass Index (BMl; calculated by multiplying a metric conversion factor of 703 by the subject's weight (lbs.) divided by their height (in.) squared) is approximately 27.3, leading to an overweight classification [31].

Table 2.1: Subject information [29].

\begin{tabular}{|l|l|}
\hline Anatomical location & Right leg \\
\hline Donor Age & 70 years \\
\hline Donor Estimated Body Weight & $170 \mathrm{lbs}$. \\
\hline Donor Height & $5^{\prime} 6^{\prime \prime}$ \\
\hline Donor Gender & Female \\
\hline Donor Cause of Death & Pneumonia/Cancer \\
\hline
\end{tabular}

\subsubsection{SOLID MODELING}

The .IGES files available from the Open Knee project page on Simtk.org (https://simtk.org/home/openknee) were imported into SolidWorks (Dassault Systèmes SolidWorks Corporation, Waltham, MA, USA) and modified slightly for meshing and eventual implementation in the FE model. Specifically, the proximal 
femur and distal tibia ends, as well as the articular cartilage and menisci edges were made planar to ease the meshing process. Additionally, artificial interferences (i.e. where the solid structures overlapped) between solid model geometry, articular cartilage, the patellar tendon, and bone surfaces were rectified in all cases by cutting away the interfering layer of soft tissue. These interferences occurred both as an unintentional product from converting the MRIs into .IGES files, as well as from merging two different generations of model geometry available on the Simtk.org depository. In general, this model includes both articulations/joints in the total knee joint: patellofemoral (articulation between the patellar and femoral articular cartilage) and tibiofemoral (articulation between the tibial and femoral articular cartilages). "Generation 1" Open Knee solid model geometry includes only the structures pertinent to the tibiofemoral joint: the femur, femoral cartilage, medial and lateral menisci, lateral and medial tibial cartilage, tibia, and ligaments (anterior cruciate, posterior cruciate, medial collateral, and lateral collateral). In order to include the patellofemoral joint components (i.e. the patella, patellar cartilage, and patellar tendon), "Generation 2" Open Knee geometry had to be merged with the "Generation 1" files. In assembling all of the desired structures in SolidWorks, interferences were observed between the patellar cartilage and patella, the patellar tendon and patella, and between the patellar tendon and distal tibia. Thus, the anterior surface of the patellar cartilage was trimmed to match the contours of the posterior aspect of the patella, the posterior surface of the patellar tendon was trimmed to match the curvature of the anterior aspect of the patella, and the 
distal patellar tendon was trimmed to match the shape of the tibial tibercule, where the patellar tendon attaches to the tibia. This approach was selected due to the comparatively high contrast available in MRIs of bone, suggesting that the geometry of these structures is most accurate as initially rendered.

After each individual part was corrected to the desirable, final form, they were assembled in SolidWorks relative to a global coordinate system aligned with default viewing planes so that they could be imported into a FE solver with their positions relative to each other preserved. The complete solid model of the knee specimen geometry is shown in Figure 2.1, along with labels of the major parts. 


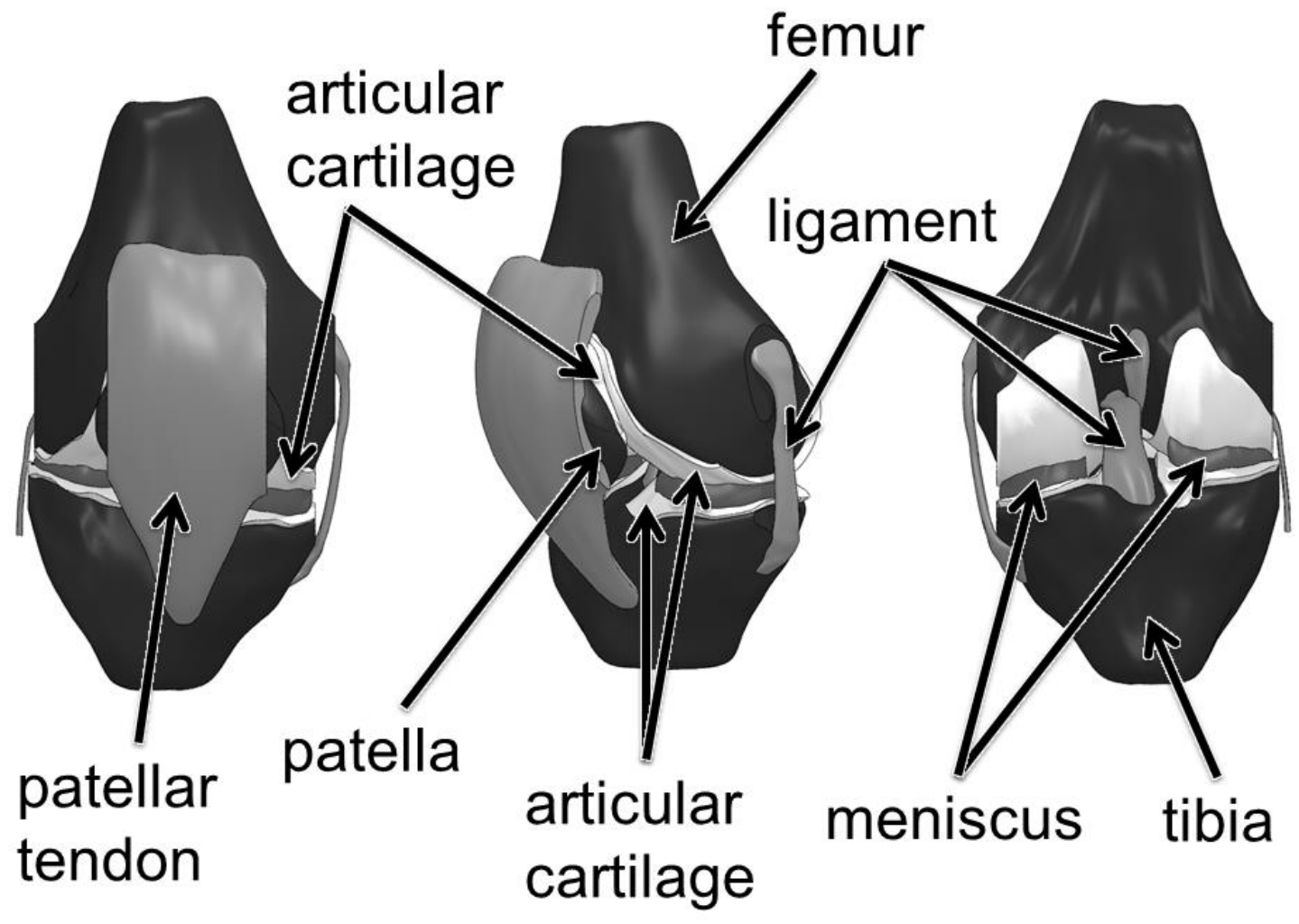

Figure 2.1: Solid model assembly of the knee-joint consisting of the distal femur, proximal tibia, patella, articular cartilage (femoral, patellar, and medial and lateral tibial), menisci (medial and lateral), ligaments (anterior cruciate, posterior cruciate, medial collateral, and lateral collateral), and patellar tendon.

\subsubsection{MESH GENERATION}

The FE mesh was produced using TrueGrid (XYZ Scientific, Livermore, CA), a mesh generation and FE pre-processing software package. Meshing a solid volume in TrueGrid can be accomplished by any number of user-specified methods and commands. Those used to mesh the knee geometry for this project utilize a process of projecting dimensions of a computational block onto points, curves, and surfaces generated from the solid model. 
For each individual component of the knee-joint (i.e. patella, medial tibial cartilage, anterior cruciate ligament, etc.), the SolidWorks part files are saved in the .IGES file format and opened directly in TrueGrid, which in turn automatically generates model geometry onto which the computational block can be projected. Ideally, the computational block can be given dimensions similar to the imported geometry and its faces can be simply projected to the proper surfaces to produce a meshed version of the SolidWorks model. However, this process makes use of a least-squared differences optimization algorithm minimizing space between the projected block and the imported geometry which does not always work as planned without significant guidance. As such, individual part files were modified in SolidWorks to include artificial divisions and curves in order to generate additional projection geometry in TrueGrid.

Table 2.2: Description of some TrueGrid commands used in meshing knee-joint geometry.

TrueGrid Description Command

block Defines a new computational block. First, the number of divisions is defined in the $\mathrm{i}, \mathrm{j}$, and $\mathrm{k}$ directions, and then each node's physical coordinates are specified.

curd Defines a numbered 3D curve. The new curve can be generated from a surface edge, automatically created curves from the .IGES importation, or from a combination of edges/curves.

cure Projects an edge of the computational mesh by distributing the edge nodes along a defined 3D curve, with the end nodes placed at the endpoints of the 3D curve.

sfi Projects a face of the computational mesh onto a numbered surface.

mseq Changes the number of elements in the $\mathrm{i}, \mathrm{j}$, or $\mathrm{k}$ direction between computational block divisions. 
In this more sophisticated process of meshing, the first step is importing the .IGES geometry file. Next, the computational block is defined with the desired mesh density (which can be refined further, later on in the process) and corresponding physical dimensions using the block command. It is desirable during this step to choose physical dimensions that locate the newly defined block just within or just beyond the imported geometry. Additionally, the number of divisions in the computational block can vastly change the orientation and overall quality of the mesh, and it is therefore possible to iterate through this and the following steps until a mesh that accurately captures the geometry of the solid part with appropriate mesh density is achieved.

Since the knee-joint component geometries are complex in shape, it is necessary to section each part into 6 -sided sections to allow for a continuous mesh to be generated. In turn, defining composite curves (curd command) and surfaces are assigned to the sections with numerical designations. Before projection of the computational block, it must be verified that this organized and refined projection geometry includes all of the desired curves and surfaces to completely characterize the body to be meshed. Finally, edges and faces of the computational block are projected onto the organized and refined projection geometry curves (cure command) and surfaces (sfi command), respectively. In this way, the optimization algorithm employed by TrueGrid can best match the meshed geometry in the physical domain to the projection geometry. Figure 2.2 diagrams the complete process of creating FE meshes from solid models of each knee-joint component. 

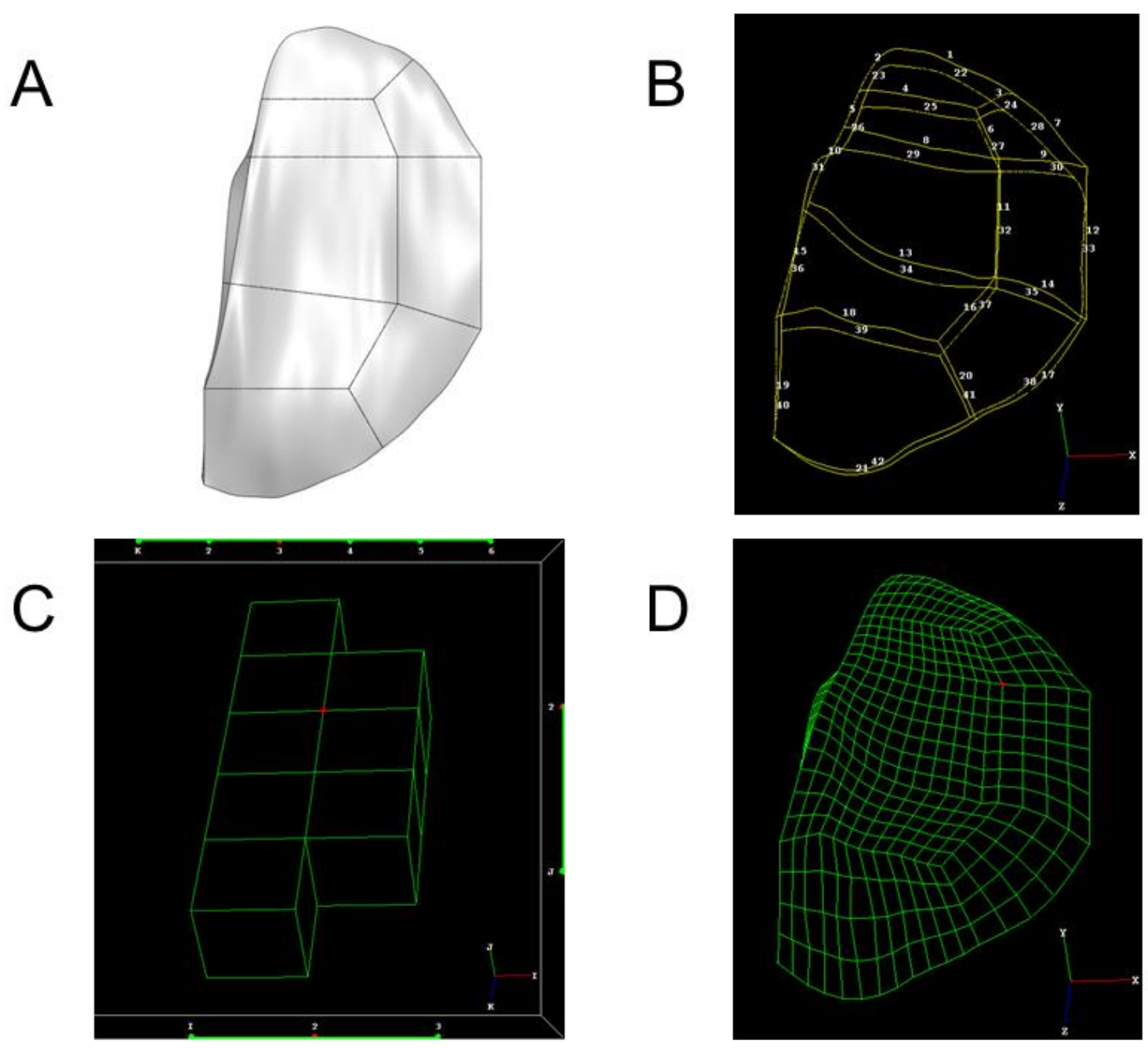

Figure 2.2: The modified medial tibial cartilage SolidWorks part file $(A)$ is saved in the .IGES file format and imported into TrueGrid. Projection curves (B) are defined with numerical designations either automatically or by converting feature edges. Finally, edges and faces of the computational block $(C)$ are projected onto the projection geometry curves and surfaces and divisions in the computational block are refined to produce the final part mesh (D).

The resulting FE mesh for the whole knee-joint is shown in Figure 2.3, and is characterized completely by linear hexahedral elements. After meshing, each part was imported into a FE solver for additional model pre-processing, described in detail in the next section. 


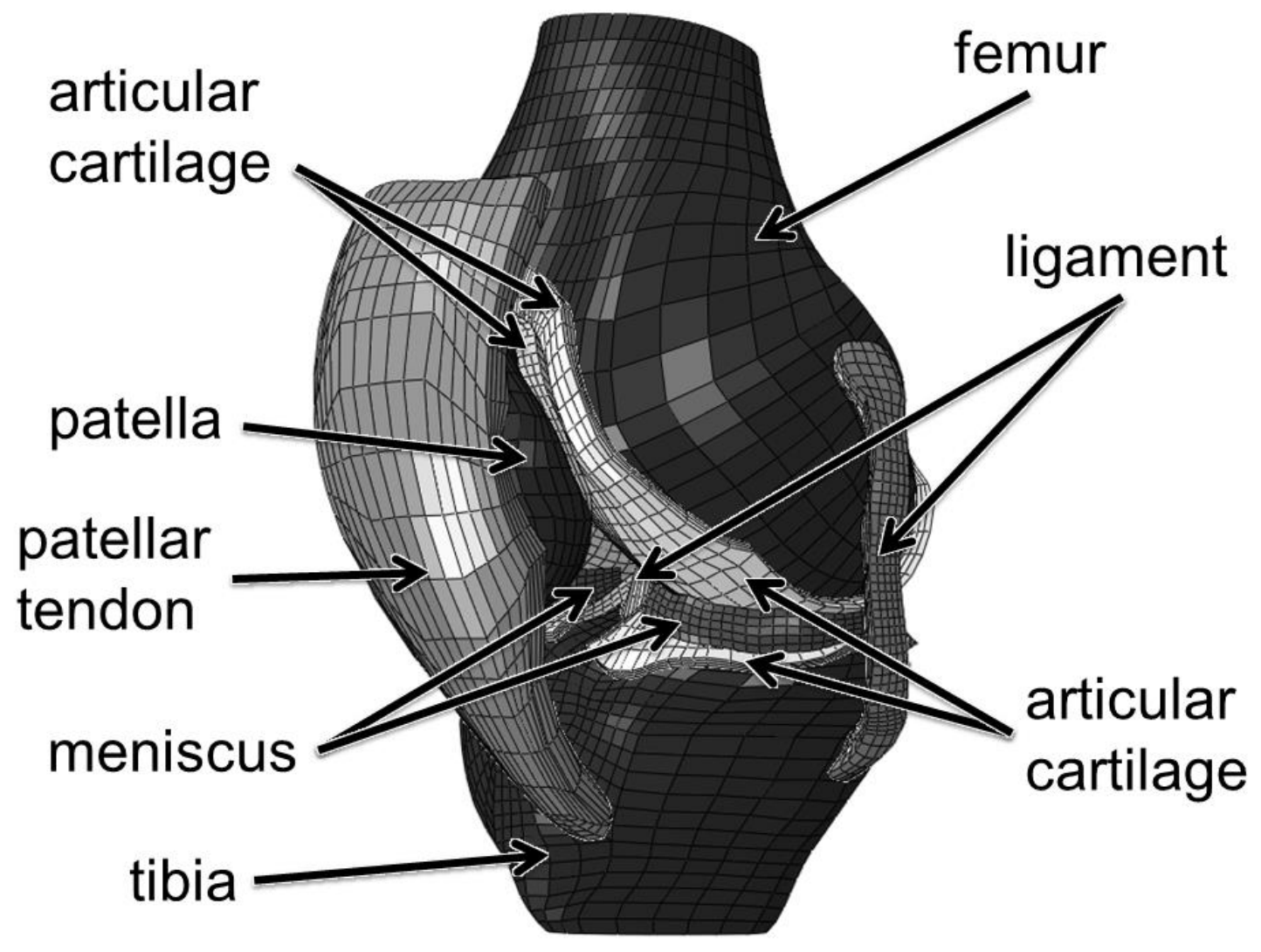

Figure 2.3: FE mesh of the knee-joint with individual components labeled.

\subsection{FINITE ELEMENT MODELING}

Abaqus (Simulia, RI, USA) is a powerful, commercially available FE solver with both pre- and post-processing capabilities than can be used to generate FE models and analyze a variety of complex geometries. In addition, it provides tools for generating meshes, as well as versatile and customizable subroutines for user defined materials and custom variables (i.e., UMATs and UVARMs). Abaqus was used as the FE solver and post-processor to view and analyze the results of this investigation. 


\subsubsection{MATERIAL PROPERTIES}

Bones were defined as completely rigid bodies for this model. This is accomplished by defining rigid body reference nodes for each bone structure, and fixing all degrees of freedom of nodes on the body to those of the reference point. As such, no strain can be developed within any of the bones, and all motions of these components are described by rigid body rotations or translations. Numerous FE studies have included rigid bones due to their high stiffness compared to other soft tissue [32, 33, 34]. It has also been shown in previous studies that defining the bones as rigid bodies has little effect on predicted stress and strain values within soft tissue structures compared to more complicated material models [35].

All articular cartilage structures (femoral, lateral and medial tibial, and patellar) were assumed to act as linear elastic, homogenous, isotropic materials with a Young's modulus of $\mathrm{E}=15 \mathrm{MPa}$ and a Poisson's ratio of 0.475 , in accordance with previous studies [35, 36]. Cartilage is often mathematically modeled as a biphasic, fibril-reinforced composite [37]. However, this model examines the single leg stance phase of the gait cycle, which exhibits short loading times compared to the viscoelastic time constant of nearly 1500 seconds for articular cartilage $[32,35,38,39]$, and articular cartilage should therefore be described by its instantaneous elastic modulus [40,41, 42]. Thus, the linear elastic, isotropic model properties used for these structures do not represent equilibrium properties, but rather dynamic properties for the rate of loading typical in gait. Therefore the Young's modulus and Poisson's ratio assigned to cartilage 
in this model for quasi-static analyses are higher than their equilibrium values, as recommended in previous studies $[35,36]$. Based on these observations, the linear elastic, isotropic model should be accurate in predicting the short-term cartilage response for the load cases examined here.

The lateral and medial menisci are also viscoelastic tissues, like articular cartilage [39]. However, similarly to articular cartilage, the short loading times during the stance phase of gait and a large viscoelastic time constant make it reasonable to model meniscus tissue as a single-phase, linear isotropic material $[32,39]$. Again, these properties are not equilibrium values, but instead represent instantaneous properties for the dynamic loading of the gait cycle. In this model, the menisci were assigned a Young's modulus of $\mathrm{E}=59 \mathrm{MPa}$ and a Poisson's ratio of 0.49 , in accordance with previous studies [32, 39].

The anterior cruciate ligament $(A C L)$, posterior cruciate ligament $(P C L)$, lateral collateral ligament (LCL), and medial collateral ligament (MCL) were assumed to act as linear elastic isotropic materials with a Poisson's ratio of 0.45 and a Young's modulus of $300 \mathrm{MPa}$. Anatomically speaking, ligaments are composed of bundled collagen fibers that run mostly in parallel along the ligament's length $[43,44]$. Mechanically, their stress-strain curves are non-linear in nature, and they act as a highly anisotropic, viscoelastic material [43, 44]. Numerous sources suggest that the Young's modulus and Poisson's ratio assumed for this model fall within an acceptable range for tension tests $[43,44$, 45]. It is assumed that these values should capture the dynamic response of the ligament tissues during gait loading. However, possible adjustments to the 
assumed material properties for ligaments in future studies are explored in the Section 4.3.3.

The patellar tendon was assigned linear elastic, transversely isotropic properties with the transverse direction of increased stiffness coinciding with the direction of pull by the quadriceps muscles (thus the plane of isotropy in the material is normal to the axis of the patellar tendon). The Young's moduli in the plane of isotropy were selected to be one order of magnitude less stiff than the modulus in the direction of pull in order to better mimic the anatomical mechanics of the structure. Using transversely isotropic material properties for ligament and tendon structures is well-established in FE studies of the knee-joint, although often a nonlinear, hyperelastic model is employed [29, 32]. Possible adjustments to the assumed material properties for the patellar tendon in future studies are explored in Section 4.3.3. It is emphasized that in this initial study with this FE model, the most simple material properties (e.g. isotropic) for all soft tissue structures were intended, but preliminary FE analyses suggested the need to model the patellar tendon as transversely isotropic in order to maintain contact in the patellofemoral joint.

Refer to Table 2.3 for a summary of the 5 independent material properties used to characterize the patellar tendon in this model (Note: the subscript " $\mathrm{t}$ " refers to the transverse direction of stiffness, and subscript "p" refers to the inplane directions of isotropy). 
Table 2.3: Summary of material properties applied to each anatomical structure. The properties for all soft tissue structures seek to capture the dynamic response of these tissues for the strain rates and loading times associated with gait. Values from previous FE studies were used for articular cartilage [35, 36] and menisci [32, 39], while the ligaments and patellar tendon have properties estimated from experimental tests [43, 44, 45].

\begin{tabular}{|c|c|c|c|}
\hline $\begin{array}{l}\text { Material } \\
\text { name }\end{array}$ & $\begin{array}{l}\text { Anatomical } \\
\text { structures }\end{array}$ & Material model & Material constants \\
\hline Bone & $\begin{array}{l}\text { Femur, Tibia, } \\
\text { Patella }\end{array}$ & Rigid body & $\mathrm{N} / \mathrm{A}$ \\
\hline $\begin{array}{l}\text { Articular } \\
\text { cartilage }\end{array}$ & $\begin{array}{l}\text { Femoral cartilage, } \\
\text { Lateral tibial } \\
\text { cartilage, Medial } \\
\text { tibial cartilage, } \\
\text { Patellar cartilage }\end{array}$ & $\begin{array}{l}\text { Linear elastic, } \\
\text { isotropic }\end{array}$ & $\begin{array}{l}E=15 \mathrm{MPa} \\
\mathrm{v}=0.475\end{array}$ \\
\hline Meniscus & $\begin{array}{l}\text { Lateral meniscus, } \\
\text { medial meniscus }\end{array}$ & $\begin{array}{l}\text { Linear elastic, } \\
\text { isotropic }\end{array}$ & $\begin{array}{l}\mathrm{E}=59 \mathrm{MPa} \\
\mathrm{v}=0.49\end{array}$ \\
\hline Ligament & $\begin{array}{l}\text { ACL, PCL, LCL, } \\
\text { MCL }\end{array}$ & $\begin{array}{l}\text { Linear elastic, } \\
\text { isotropic }\end{array}$ & $\begin{array}{l}E=300 \mathrm{MPa} \\
\mathrm{v}=0.45\end{array}$ \\
\hline $\begin{array}{l}\text { Patellar } \\
\text { tendon }\end{array}$ & Patellar tendon & $\begin{array}{l}\text { Linear elastic, } \\
\text { transversely } \\
\text { isotropic }\end{array}$ & $\begin{array}{l}\mathrm{E}_{\mathrm{p}}=30 \mathrm{MPa}, \mathrm{E}_{\mathrm{t}}=300 \mathrm{MPa} \\
\mathrm{v}_{\mathrm{p}}=0.45, \mathrm{v}_{\mathrm{pt}}=0.045 \\
\mathrm{G}_{\mathrm{t}}=20 \mathrm{MPa}\end{array}$ \\
\hline
\end{tabular}

\subsubsection{CONTACT INTERACTIONS}

Surface-to-surface contact between parts of the knee-joint was defined for 7 discrete contact pairs:

1. femoral cartilage to lateral meniscus

2. femoral cartilage to medial meniscus

3. femoral cartilage to lateral tibial cartilage

4. femoral cartilage to medial tibial cartilage

5. lateral tibial cartilage to lateral meniscus

6. medial tibial cartilage to medial meniscus

7. patellar cartilage to femoral cartilage

In each case, a frictionless, finite sliding formulation was used. This selection is well-established in past FE studies [32, 35, 46]. Other literature 
sources also indicate that the fluid pressure within the tissues carry a substantial amount of the load during the short loading times associated with gait, resulting in very low or negligible friction evolved between articular cartilage surfaces [47, 48].

\subsubsection{RIGID BODY TIE CONSTRAINTS}

Attachments between soft tissues and bones were achieved through rigid body tie constraints. In this formulation, all the degrees of freedom of nodes on the fastening surface of a ligament or articular cartilage structure are held fixed with respect to the rigid body reference point of the appropriate bone. For this model, 3 distinct rigid body tie constraints exist, corresponding to each of the 3 bone structures. Attaching to the femur, node sets include all nodes on the attaching surfaces of the femoral cartilage, and the proximal faces of the ACL, PCL, LCL, and MCL. The set attaching to the tibia includes all nodes on the distal faces of the lateral and medial tibial cartilages, and all nodes on the distal faces of the ACL, PCL, LCL, MCL, and patellar tendon. Finally, the set of nodes attaching to the patella include all nodes on the anterior face of the patellar cartilage and the posterior face of the patellar tendon. The displacements of the

menisci were also constrained, but not through the use of rigid body tie constraints. Instead, restrictions on their motion are discussed in Section 2.2.5, through the use of boundary conditions.

\subsubsection{LOADS}

Loads applied to the knee-joint model were determined from an opensource, musculoskeletal modeling software called OpenSim (National Center for 
Simulation in Rehabilitation Research, Stanford University). The OpenSim software package was developed to allow users to perform and analyze dynamic simulations of the human musculoskeletal system [49]. In this thesis, OpenSim was used by California Polytechnic State University General Engineering graduate Kevin Jones, under direction of this thesis' author, to obtain joint contact forces in the knee-joint and quadriceps muscle forces (which include 4 distinct muscles that channel into the patellar tendon) during the stance phase of gait from externally obtained experimental marker data.

OpenSim's Gait 2392 model of the lower leg was used for simulations to determine joint contact forces and moments for the stance phase of gait. The Gait 2392 model represents the human musculoskeletal system with rigid bones, a total of 23 degrees of freedom at the joints, and 92 actuators representing 76 muscles active in motions of the lower limbs [50]. The length, inertial, and mass properties of body segments in this generic model are scaled by experimental marker data obtained from the Multiple Speed Walking Simulations project [51], available for download from Simtk.org (https://simtk.org/home/mspeedwalksims). Marker data from Subject 6, a female weighing 180.6 pounds and having a leg length of 3.1 feet, includes the locations of several visual markers on each bone segment at numerous discrete time steps (obtained originally from a motion capture system), as well as ground reaction forces and moments measured by a force plate throughout one complete gait cycle at a walking speed of $2.51 \mathrm{mph}$ $(1.12 \mathrm{~m} / \mathrm{s})$ [51]. This subject was selected for her similar gender, height, and weight to the subject from whom the FE model geometry was developed. With 
the Subject 6 experimental marker motion data loaded into the Gait 2392 lower limb model, OpenSim is used to perform an inverse dynamics step. The Inverse Dynamics (ID) Tool calculates the acceleration of each bone segment's center of mass from the marker data and uses the corresponding ground reaction forces/moments at that time step to solve for the net forces and moments at each joint required to produce that motion [52]. However, it should be noted that ID does not account for muscle activation when calculating joint forces/moments. Therefore, the Static Optimization (SO) Tool is used to further resolve the joint forces/moments calculated by ID into discrete muscle forces at the sites of the 92 actuators described above. Generally speaking, this is an under-defined quasistatic analysis. As such, OpenSim utilizes an optimization algorithm that seeks to minimize the sum of the square muscle activation energies [53]. Subsequently, Joint Reactions Analysis (JRA) is used for calculating the total joint reaction forces and moments, this time including the contributions of muscle activations, at the knee-joint throughout the gait cycle [54].

The loads applied to the FE model were determined from SO and JRA at 6 discrete time steps of the right leg stance phase of the gait cycle (expressed as a percentage of the total time for this phase): $0 \%$ (heel strike), $5 \%, 25 \%, 50 \%$, $75 \%$, and $100 \%$ (toe off). The joint contact forces and moments obtained from JRA are applied at the knee-joint center, defined in OpenSim at the midpoint of the femoral epicondyles. Since the femur is defined as a rigid body in the FE model, all loads acting on it must be applied at its rigid body reference point. For convenience, this point was positioned to coincide with the OpenSim joint center, 
and a local coordinate system was established to align with the OpenSim output coordinate system (x-axis normal to the frontal plane, $y$-axis normal to the transverse plane and pointing proximally, and z-axis normal to the sagittal plane and pointing laterally). The quadriceps muscle forces obtained from SO are applied as a single resultant muscle pressure on the proximal face of the patellar tendon, and normal to this surface. At each of the 6 time steps mentioned above, the 4 distinct quadriceps muscle forces solved for by SO are combined into a resultant magnitude and divided by the proximal patellar tendon surface area $\left(169.697 \mathrm{~mm}^{2}\right)$, yielding an effective quadriceps muscle pressure to be applied in the FE model.

Table 2.4: Summary of loads implemented in the FE model for 6 discrete stages of the stance phase of gait.

\begin{tabular}{|c|c|c|c|c|c|c|c|c|}
\hline \multirow{2}{*}{$\begin{array}{l}\text { Percent } \\
\text { of } \\
\text { stance } \\
\end{array}$} & \multirow{2}{*}{$\begin{array}{c}\text { Knee } \\
\text { flexion } \\
\text { angle } \\
(\mathrm{rad})\end{array}$} & \multirow{2}{*}{$\begin{array}{c}\text { Quadriceps } \\
\text { muscle } \\
\text { pressure } \\
(\mathrm{MPa})\end{array}$} & \multicolumn{3}{|c|}{ Joint reaction forces $(\mathrm{N})$} & \multicolumn{3}{|c|}{$\begin{array}{c}\text { Joint reaction } \\
\text { moments }(\mathrm{N}-\mathrm{mm})\end{array}$} \\
\hline & & & $\mathrm{Fx}$ & Fy & $\mathrm{Fz}$ & $\mathrm{Mx}$ & My & $\mathrm{Mz}$ \\
\hline $0 \%$ & 0.183 & 1.193 & 366.0 & -769.4 & 3.0 & 1732 & 2593 & 3001 \\
\hline $5 \%$ & 0.230 & 1.483 & 458.1 & -1058.6 & -26.3 & 5781 & 4053 & 3557 \\
\hline $25 \%$ & 0.363 & 4.275 & 629.9 & -1907.9 & -138.6 & -15484 & 7962 & 14110 \\
\hline $50 \%$ & 0.214 & 0.771 & 40.1 & -1414.4 & -11.0 & -22709 & 411 & 6392 \\
\hline $75 \%$ & 0.170 & 0.776 & -434.1 & -2411.8 & -23.0 & -38492 & -3445 & 8331 \\
\hline $100 \%$ & 0.424 & 1.282 & -464.1 & -1547.2 & -23.5 & -27662 & 3087 & 4389 \\
\hline
\end{tabular}

Due to the rigid body definition of the bones, and the imposed boundary conditions in the model (discussed in more detail in the following section), the loading condition described above most accurately captures the anatomical loading during the gait cycle without including every individual muscle force. The JRA resultant joint contact forces and moments applied to the femur at the joint 
center capture the effects of the ground reactions as well as muscle force contributions crossing the tibiofemoral joint. The quadriceps muscle forces obtained from SO are the only muscle forces that act directly on the patellofemoral joint, and therefore must also be included to maintain contact in this area. Since these forces only cross the tibiofemoral joint by transmission through the modeled patellar tendon, it is important to represent them separately from the joint reactions at the knee-joint center.

It is important to note here that there is still some uncertainty from reviewing the literature about how OpenSim results should be applied to the model. It is not clear, for example, if the contributions of the quadriceps muscles (acting on the patellofemoral joint) are also included in the joint reaction forces and moments calculated by JRA and presented at the knee joint center. If this were the case, the statically equivalent force/couple of the 4 quadriceps muscle forces should be subtracted from the loads applied to the femoral rigid body reference point in this FE model. These uncertainties must be examined in future work with OpenSim (discussed in further detail in Section 4.3.2) in order to ensure accurate model results.

\subsubsection{BOUNDARY CONDITIONS}

All displacements and rotations of tibia were fixed throughout the simulation. Knee joint flexion angles were obtained from OpenSim at each of the 6 discrete time points in the gait cycle and applied as an angular displacement boundary condition to the femur, rotating it about the local z-axis (passing through the joint center reference point) in a rotation step before the loads were 
applied. This rotation was then held fixed as the loads corresponding to that flexion angle were applied to the femur and patellar tendon. All other rotation directions of the femur (i.e. about the local $x$ and $y$ axes) were left unconstrained.

In addition to boundary conditions applied to the bones, the motion of the lateral and medial menisci was restricted to maintain their positions between the femoral and tibial cartilages. Preliminary analyses showed this was necessary to keep the menisci from displacing out of the joint. Nodes on the medial faces of the lateral meniscus and the lateral faces of the medial meniscus were constrained in the local z-direction (i.e. they were confined to motion in the sagittal plane). Additionally, the nodes along the interior edges of these faces, running inferior-superior, were constrained in the local $x$-direction. Thus, the menisci were fixed at their approximate locations between the femoral and tibial cartilages and not allowed to dilate outward under load. This procedure has precedent in a past study [32]. Other FE studies have proposed more anatomically accurate ways of defining the menisci's attachments to the tibia, which will be outlined in detail in Section $4.3 .4[35,46,55]$. 


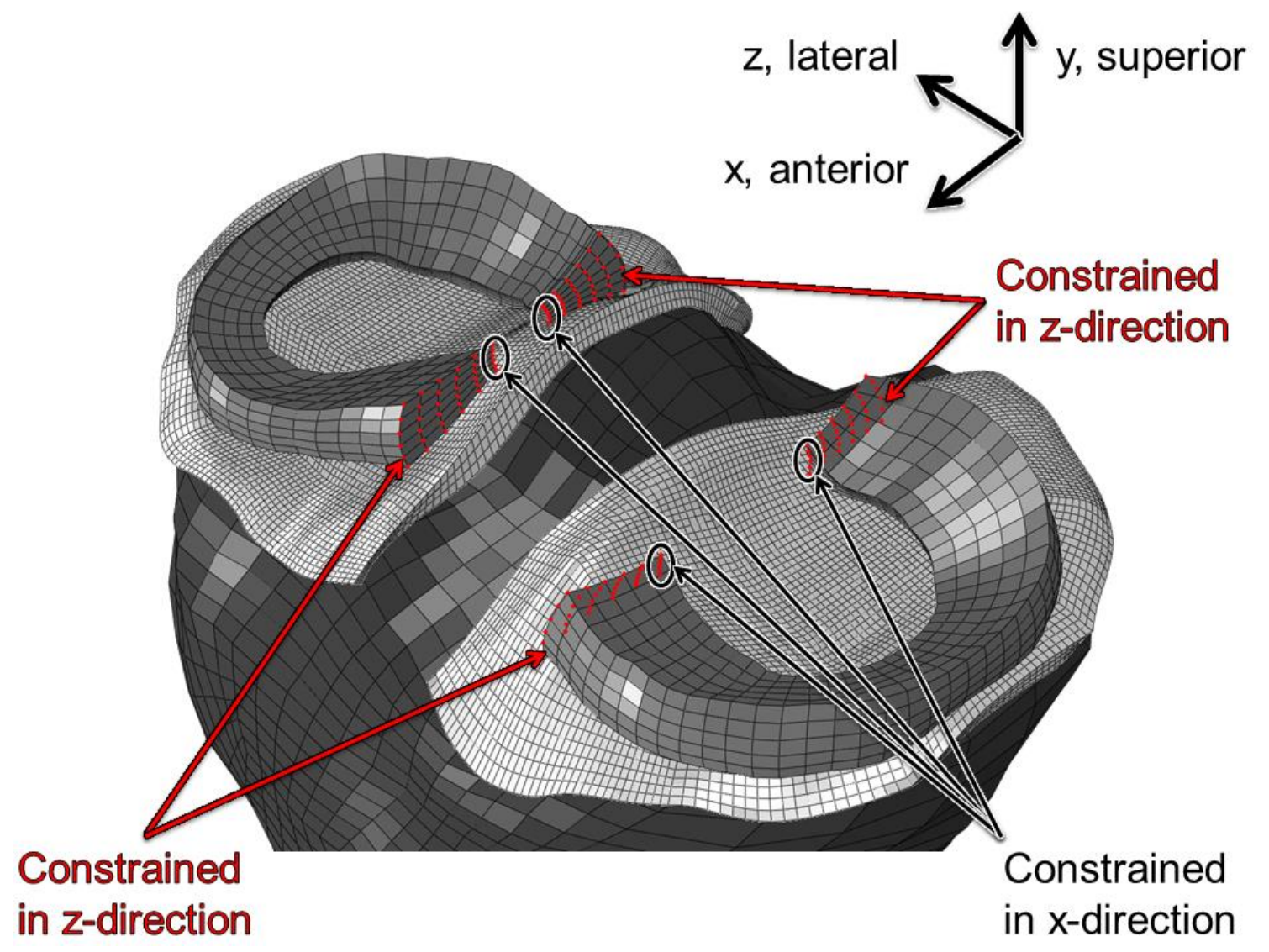

Figure 2.4: Tibia, lateral and medial tibial articular cartilages, and lateral and tibial menisci with menisci boundary conditions labeled. Nodes on the medial faces of the lateral meniscus and the lateral faces of the medial meniscus were constrained in the local z-direction, and nodes along the interior edges of these faces, running inferior-superior, were constrained in the local $x$-direction.

\subsubsection{MESH CONVERGENCE}

A mesh convergence study was performed on articular cartilage structures only because analyzing cartilage stress and strain was the goal due to the focus on OA. To accomplish this, 8 different versions of each articular cartilage surface were produced in TrueGrid. The global mesh seed size was matched across the 4 different parts for each qualitative mesh density. Node sets were defined for each articular cartilage structure at the junction of computational block edges such that those node locations were known to be in the same physical position 
on the part regardless of mesh density. This resulted in 4 nodes on the femoral cartilage, 4 nodes on the medial tibial cartilage, 3 nodes on the medial tibial cartilage, and 3 nodes on the patellar cartilage.

For each qualitative mesh density designation, maximum shear stress and strain were tracked at each of the convergence nodes, as well as the maximum value within each individual tissue. Figure 2.5 shows these values plotted against total model variables, a quantity calculated by Abaqus and representative of the mesh density and increases/decreases in computational time required based on material properties, restricting boundary conditions, and other model parameters.
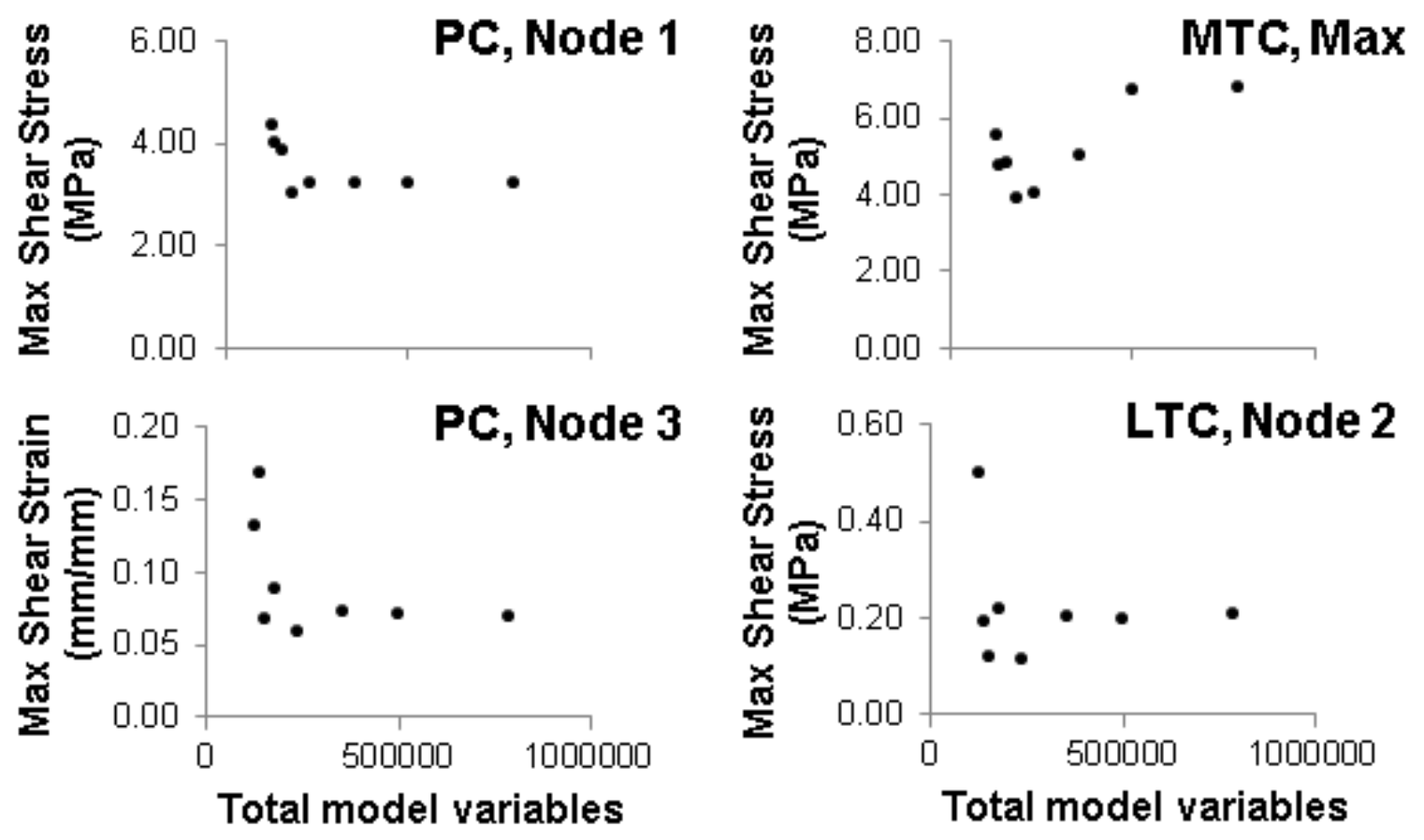

Figure 2.5: Convergence study results shown for convergence node 1 of the patellar cartilage (PC), convergence node 2 of the lateral tibial cartilage (LTC), convergence node 3 of the $\mathrm{PC}$, and the maximum value on the medial tibial cartilage (MTC). 
These convergence plots show that the maximum shear stress and strain appear to converge for the articular cartilage meshes corresponding to 502371 total model variables in several locations throughout the model. However, it is important to note here that the junctions of computational block edges where convergence nodes were defined do not always align with areas of interest (i.e. high stress/strain) on the articular cartilage. Additionally, stress concentrations occur on articular cartilage surfaces in the tibiofemoral joint due to sharp edges on the lateral and medial meniscus meshes and the boundary conditions confining these structures in place. Therefore, convergence is not achieved for the maximum value occurring on the tissue of the output variables examined for the femoral, lateral tibial, and medial tibial articular cartilages. Output parameters such as maximum shear stress and strain in these areas should be considered with additional caution for this reason. However, since good convergence is found in other areas of the model for this global seed size, it is assumed that mesh convergence is reasonably satisfied for this model, and this area should be revisited in future studies (see discussion in Chapter 4).

Due to uncertainties associated with the stress concentrations described above, the finest articular cartilage mesh was selected over the 502371 total model variables mesh to ensure the best convergence throughout the model. As such, a total of 81039 articular cartilage elements (36636 femoral, 15354 lateral tibial, 12975 medial tibial, and 16074 patellar cartilage elements) demonstrated satisfactory convergence in all other locations. This translates to a total of 794100 model variables. 


\subsubsection{DAMPING STABILIZATION FACTOR}

Modeling contact interactions present an inherent convergence problem. One approach to mitigate this problem is including a damping stabilization factor in the computational model. This form of automatic stabilization aids Abaqus in finding a solution for cases of complex material contact interactions, in this case, occurring between the articular cartilages and menisci. The term "damping" is used here to indicate energy dissipated. For unstable problems, the damping stabilization factor serves as a non-physical work-around to dissipate instabilities in the solution state at the end of each solution increment. While damping stabilization helps the FE solver find a solution, it also can negatively affect the accuracy of the solution if the factor causes the ratio of artificially imposed dissipative viscous forces to total forces within the model to become too large. Thus, a large damping stabilization factor will result in large dissipative viscous forces in the model, resulting in a large fraction of the energy applied via loads to be lost. However, if implemented correctly, the damping stabilization factor can minimally impact the results while greatly reducing computational time and enabling a solution to be found. Table 2.5 shows the damping stabilization factors used for each loading case in this FE model.

Abaqus issues a warning message if it detects excessive damping within the model. This warning was never observed for any of the different loading conditions examined in this thesis. Table 2.5 shows comparisons of viscous forces (VF) to total forces (TF) within the model. Since these proportions are less than $10 \%$, it is assumed that viscous forces do not dominate within the 
model. This concept will need to be evaluated in future work to confirm that the effect of these damping stabilization factors on the output parameters of interest is minimal.

Table 2.5: Damping stabilization factors used for each loading case and their respective ratios of viscous force (VF) to total forces (TF).

\begin{tabular}{lll}
$\begin{array}{l}\text { Percent } \\
\text { of gait }\end{array}$ & $\begin{array}{l}\text { Damping } \\
\text { stabilization } \\
\text { factor }\end{array}$ & VF/TF \\
\hline 0 & 0.002 & 0.032 \\
5 & 0.002 & 0.033 \\
25 & 0.002 & 0.028 \\
50 & 0.002 & 0.042 \\
75 & 0.010 & 0.085 \\
100 & 0.002 & 0.087 \\
\hline
\end{tabular}

\subsubsection{OUTPUT VARIABLES}

The output variables for this FE model include contact pressure (CPRESS), contact area (CNAREA), stress components and invariants $(S)$, and logarithmic strain components $(L E)$. The Abaqus standard stress output variable, $S$, includes minimum and maximum principal stress, as well as maximum shear stress. $L E$ is the only allowable output strain formulation for cases of large deformations and non-linear geometry, like those present in this model. However, it has been shown in previous experimental studies that GreenLagrangian principal and maximum shear strains are among the most important indicators of cell death within cartilage tissue [56], [57]. Thus, a user-defined variable (UVARM) subroutine was implemented to convert the maximum and minimum principal logarithmic strains to the desired Green-Lagrangian 
equivalents. Since the principal stretches for $L E$ (derived from the left-Cauchy deformation tensor) and Green-Lagrangian strain (derived from the right-Cauchy deformation tensor) are the same, the conversion (outlined below), is fairly straightforward.

Let $\boldsymbol{F}$ be the deformation gradient tensor. The right Cauchy-Green deformation tensor, $\boldsymbol{C}$ and the left Cauchy-Green deformation tensor, $\boldsymbol{B}$ are defined as:

$$
\begin{aligned}
& \boldsymbol{C}=\boldsymbol{F}^{T} \boldsymbol{F} \\
& \boldsymbol{B}=\boldsymbol{F} \boldsymbol{F}^{T}
\end{aligned}
$$

The deformation gradient tensor, $\boldsymbol{F}$ can be decomposed into two parts via the polar decomposition theorem:

$$
F=R U=V R
$$

Where $\boldsymbol{R}$ is a proper orthogonal tensor representing a rotation, $\boldsymbol{U}$ is the right stretch tensor, and $\boldsymbol{V}$ is the left stretch tensor. Since $\boldsymbol{R}$ is proper orthogonal, and both $\boldsymbol{U}$ and $\boldsymbol{V}$ are symmetric, positive-definite:

$$
\begin{gathered}
\boldsymbol{R}^{-1}=\boldsymbol{R}^{T} \\
\boldsymbol{U}=\boldsymbol{U}^{T} \\
\boldsymbol{V}=\boldsymbol{V}^{T}
\end{gathered}
$$


Applying these results with the deformation gradient's polar decomposition, $\boldsymbol{C}$ and $\boldsymbol{B}$ can be expressed as:

$$
\begin{aligned}
& C=U^{2} \\
& B=V^{2}
\end{aligned}
$$

For three distinct principal stretches, $\lambda_{i}$ the spectral decompositions of $\boldsymbol{C}$ and $\boldsymbol{B}$ are defined in their eigenbases by:

$$
\begin{aligned}
& \boldsymbol{C}=\sum_{i=1}^{3} \lambda_{i}{ }^{2} \boldsymbol{N}_{i} \otimes \boldsymbol{N}_{i} \\
& \boldsymbol{B}=\sum_{i=1}^{3} \lambda_{i}{ }^{2} \boldsymbol{n}_{i} \otimes \boldsymbol{n}_{i}
\end{aligned}
$$

Where $\boldsymbol{N}_{i}$ are eigenvectors in the reference configuration and $\boldsymbol{n}_{\boldsymbol{i}}$ are eigenvectors in the current configuration. Thus, the principal stretches (eigenvalues), $\lambda_{i}$ are the same for both $\boldsymbol{C}$ and $\boldsymbol{B}$, but their principal directions (eigenvectors) differ. Substituting, $\boldsymbol{V}$ can be rewritten:

$$
\boldsymbol{V}=\sum_{i=1}^{3} \lambda_{i} \boldsymbol{n}_{i} \otimes \boldsymbol{n}_{i}
$$

Logarithmic strain, $\varepsilon_{L}$ is defined as the natural log of the left stretch tensor:

$$
\varepsilon_{L}=\ln \boldsymbol{V}=\sum_{i=1}^{3} \ln \lambda_{i} \boldsymbol{n}_{i} \otimes \boldsymbol{n}_{i}=\sum_{i=1}^{3} \varepsilon_{L i} \boldsymbol{n}_{i} \otimes \boldsymbol{n}_{i}
$$

Therefore, using this result: 


$$
\begin{gathered}
\ln \lambda_{i}=\varepsilon_{L_{i}} \\
\lambda_{i}=e^{\varepsilon_{L_{i}}}
\end{gathered}
$$

Green-Lagrangian strain, $\boldsymbol{E}$ is defined with respect to the left CauchyGreen deformation tensor:

$$
\boldsymbol{E}=\frac{1}{2}(C-I)=\sum_{i=1}^{3} \frac{1}{2}\left(\lambda_{i}^{2}-\boldsymbol{I}\right) \boldsymbol{N}_{i} \otimes \boldsymbol{N}_{i}
$$

Finally, noting again that the principal stretches used for the formulation of $\boldsymbol{E}$ and $\varepsilon_{L}$, the principal values of logarithmic strain can be used to calculate the principal values of Green-Lagrangian strain:

$$
E_{i}=\frac{1}{2}\left[\left(e^{\varepsilon_{L i}}\right)^{2}-1\right]
$$

Maximum shear Green-Lagrange strains were calculated using:

$$
\gamma=\frac{E_{\max }-E_{\min }}{2}
$$

Where $E_{\max }$ is the maximum principal Green-Lagrangian strain and $E_{\min }$ is the minimum principal Green-Lagrangian strain. The UVARM subroutine used to calculate Green-Lagrangian principal strains and maximum shear strain is included in Appendix A for reference.

\subsubsection{COMPUTER SPECIFICATIONS}

All analyses in this thesis were performed with 2 custom built workstations, each with Intel Core i7-950 3.06 GHz quad-core processors, ASUS 
P6X58D premium motherboards, and 12 GB RAM. Each ran with the Linux Fedora, version 10 operating system. Simulation wall-clock times range from 56.65 minutes ( 3.86 hours CPU time) for $0 \%$ of stance to 7.98 hours (20.75 hours CPU time) for $5 \%$ of stance. All other simulation run times fell within this range. 


\title{
CHAPTER 3
}

\author{
RESULTS
}

Contour plots of contact pressure, maximum principal (maximum tensile) Green-Lagrangian strain, and maximum shear Green-Lagrangian strain for each of the 6 loading conditions examined are included on the following pages of this section. Mentioned earlier, experimental studies have shown that articular cartilage damage and cell death are correlated to maximum shear strain, occurring at strains in excess of $20 \%$ in impact studies [56, 57, 58], although strain rate also appears to play a significant role $[58,59]$. Additionally, it has been shown that maximum principal strain is also a factor in articular cartilage damage [57]. It is for this reason that the maximum shear strain and maximum principal strain plots were included in Figure 3.2 on page 40 and Figure 3.3 on page 41 , respectively. Refer to Section 4.3 .9 for additional discussion regarding articular cartilage damage and cell death comparisons in future work.

The maximum contact pressure observed was $16.036 \mathrm{MPa}$ in the medial tibial cartilage at $75 \%$ of stance. Table 3.1 gives the maximum contact pressures for different aspects of each articular cartilage structure. Also at $75 \%$ of stance, a maximum contact area of $2328.44 \mathrm{~mm}^{2}$ was predicted on the inferior aspect of the femoral cartilage. It follows that this is a reasonable location for the 
maximum observed contact area across all articular cartilage tissues because contact on the inferior aspect of the femoral cartilage includes the contributions of contact with both the medial and lateral tibial cartilages. Table 3.2 gives all total contact areas measured on different aspects of each articular cartilage structure.

Table 3.1: Maximum contact pressure (MPa) predicted by the FE Model on different aspects of each articular cartilage structure.

\begin{tabular}{c|ccccc} 
& \multicolumn{5}{|c}{ Maximum contact pressure (MPa) } \\
$\begin{array}{c}\text { Percent } \\
\text { of } \\
\text { stance }\end{array}$ & $\begin{array}{c}\text { Femoral } \\
\text { cartilage }\end{array}$ & $\begin{array}{c}\text { Tibial } \\
\text { cartilage }\end{array}$ & $\begin{array}{c}\text { Patellar } \\
\text { cartilage }\end{array}$ \\
\hline $0 \%$ & 2.82 & 8.63 & 9.17 & 6.15 & 2.83 \\
$5 \%$ & 3.19 & 12.14 & 12.38 & 6.90 & 3.20 \\
$25 \%$ & 5.43 & 10.54 & 15.49 & 13.99 & 5.44 \\
$50 \%$ & 2.54 & 10.65 & 4.57 & 14.61 & 2.57 \\
$75 \%$ & 0.00 & 11.64 & 5.07 & 16.04 & 0.00 \\
$100 \%$ & 0.00 & 14.22 & 2.94 & 15.67 & 0.00 \\
\hline
\end{tabular}

Table 3.2: Total contact area $\left(\mathrm{mm}^{2}\right)$ predicted by the FE model on different aspect of each articular cartilage structure.

\begin{tabular}{c|ccccc} 
& \multicolumn{5}{|c}{ Contact Area $\left(\mathrm{mm}^{2}\right)$} \\
$\begin{array}{c}\text { Percent } \\
\text { of } \\
\text { stance }\end{array}$ & $\begin{array}{c}\text { Femoral } \\
\text { cartilage }\end{array}$ & $\begin{array}{c}\text { Tibial } \\
\text { cartilage }\end{array}$ & $\begin{array}{c}\text { Patellar } \\
\text { cartilage }\end{array}$ \\
\hline $0 \%$ & 683.0 & 1367.9 & 681.1 & 995.9 & 682.9 \\
$5 \%$ & 778.1 & 1786.1 & 890.4 & 1091.5 & 777.9 \\
$25 \%$ & 1180.6 & 2129.9 & 567.6 & 1712.2 & 1180.5 \\
$50 \%$ & 177.1 & 1727.9 & 215.8 & 1719.5 & 177.0 \\
$75 \%$ & 0.0 & 2328.4 & 296.2 & 1987.1 & 0.0 \\
$100 \%$ & 0.0 & 2005.7 & 325.8 & 1833.5 & 0.0 \\
\hline
\end{tabular}


A minimum principal Green-Lagrangian strain of $31.3 \%$ was predicted on the femoral cartilage at $75 \%$ stance, and was the largest magnitude across all articular cartilage structures. This prediction is well above possible threshold values for articular cartilage damage, discussed earlier. Refer to Chapter 4 for discussion comparing these values to past work, reasons why these strains may be over-estimated, and possible solutions moving forward with this model. Table 3.3 shows the minimum principal Green-Lagrangian strains occurring on different aspects of each articular cartilage structure.

Table 3.3: Minimum principal Green-Lagrangian strain $(\mathrm{mm} / \mathrm{mm})$ predicted by the FE model on different aspects of each articular cartilage structure. Negative values indicate that the strains are compressive. Strains on each structure are divided by those occurring throughout the entire thickness of articular cartilage geometry (overall) and those occurring on the contact surface with other kneejoint structures (on contact surface).

\begin{tabular}{|c|c|c|c|c|c|c|c|c|}
\hline \multirow[b]{4}{*}{$\begin{array}{l}\text { Percent } \\
\text { of } \\
\text { stance }\end{array}$} & \multicolumn{8}{|c|}{ Minimum principal Green-Lagrangian strain $(\mathrm{mm} / \mathrm{mm})$} \\
\hline & \multirow{2}{*}{\multicolumn{2}{|c|}{$\begin{array}{l}\text { Femoral } \\
\text { cartilage }\end{array}$}} & \multicolumn{4}{|c|}{ Tibial cartilage } & \multirow{2}{*}{\multicolumn{2}{|c|}{ Patellar cartilage }} \\
\hline & & & & eral & & dial & & \\
\hline & Overall & $\begin{array}{c}\text { On } \\
\text { contact } \\
\text { surface } \\
\end{array}$ & Overall & $\begin{array}{c}\text { On } \\
\text { contact } \\
\text { surface }\end{array}$ & Overall & $\begin{array}{c}\text { On } \\
\text { contact } \\
\text { surface }\end{array}$ & Overall & $\begin{array}{c}\text { On } \\
\text { contact } \\
\text { surface }\end{array}$ \\
\hline $0 \%$ & -0.246 & -0.165 & -0.229 & -0.229 & -0.160 & -0.160 & -0.095 & -0.095 \\
\hline $5 \%$ & -0.342 & -0.244 & -0.275 & -0.275 & -0.183 & -0.183 & -0.104 & -0.104 \\
\hline $25 \%$ & -0.242 & -0.186 & -0.276 & -0.276 & -0.273 & -0.273 & -0.162 & -0.162 \\
\hline $50 \%$ & -0.255 & -0.217 & -0.151 & -0.151 & -0.276 & -0.276 & -0.089 & -0.089 \\
\hline $75 \%$ & -0.313 & -0.223 & -0.155 & -0.155 & -0.289 & -0.289 & -0.003 & -0.001 \\
\hline $100 \%$ & -0.297 & -0.231 & -0.102 & -0.102 & -0.279 & -0.279 & -0.006 & -0.002 \\
\hline
\end{tabular}

The largest magnitude maximum principal Green-Lagrangian strain predicted was $70.5 \%$, occurring on the lateral tibial cartilage at $25 \%$ of stance. Again, this prediction is much greater than the suggested threshold values for 
articular cartilage damage. Refer to Chapter 4 for a detailed discussion of the implications of these results. Table 3.4 shows the maximum principal GreenLagrangian strains occurring on different aspects of each articular cartilage structure.

Table 3.4: Maximum principal Green-Lagrangian strain $(\mathrm{mm} / \mathrm{mm})$ predicted by the FE model on different aspects of each articular cartilage structure. Strains on each structure are divided by those occurring throughout the entire thickness of articular cartilage geometry (overall) and those occurring on the contact surface with other knee-joint structures (on contact surface).

\begin{tabular}{|c|c|c|c|c|c|c|c|c|}
\hline \multirow[b]{4}{*}{$\begin{array}{c}\text { Percent } \\
\text { of } \\
\text { stance }\end{array}$} & \multicolumn{8}{|c|}{ Maximum principal Green-Lagrangian strain $(\mathrm{mm} / \mathrm{mm})$} \\
\hline & \multirow{2}{*}{\multicolumn{2}{|c|}{$\begin{array}{l}\text { Femoral } \\
\text { cartilage }\end{array}$}} & \multicolumn{4}{|c|}{ Tibial cartilage } & \multirow{2}{*}{\multicolumn{2}{|c|}{ Patellar cartilage }} \\
\hline & & & Lat & eral & & dial & & \\
\hline & Overall & $\begin{array}{c}\text { On } \\
\text { contact } \\
\text { surface }\end{array}$ & Overall & $\begin{array}{c}\text { On } \\
\text { contact } \\
\text { surface }\end{array}$ & Overall & $\begin{array}{c}\text { On } \\
\text { contact } \\
\text { surface }\end{array}$ & Overall & $\begin{array}{c}\text { On } \\
\text { contact } \\
\text { surface } \\
\end{array}$ \\
\hline $0 \%$ & 0.277 & 0.154 & 0.262 & 0.262 & 0.167 & 0.167 & 0.060 & 0.060 \\
\hline $5 \%$ & 0.543 & 0.271 & 0.392 & 0.392 & 0.174 & 0.174 & 0.069 & 0.069 \\
\hline $25 \%$ & 0.384 & 0.222 & 0.705 & 0.705 & 0.286 & 0.286 & 0.141 & 0.101 \\
\hline $50 \%$ & 0.399 & 0.234 & 0.132 & 0.132 & 0.310 & 0.310 & 0.062 & 0.062 \\
\hline $75 \%$ & 0.605 & 0.260 & 0.142 & 0.142 & 0.372 & 0.362 & 0.002 & 0.001 \\
\hline $100 \%$ & 0.459 & 0.245 & 0.076 & 0.076 & 0.402 & 0.402 & 0.004 & 0.001 \\
\hline
\end{tabular}


Finally, the maximum shear Green-Lagrangian strain predicted across all articular cartilages was $45.9 \%$ on the femoral cartilage at $75 \%$ of stance. Still, this prediction is much greater than the suggested threshold values for articular cartilage damage for maximum shear strains. Refer to Chapter 4 for a detailed discussion of the implications of these results. Table 3.5 shows the maximum shear Green-Lagrangian strains occurring on different aspects of each articular cartilage structure.

Table 3.5: Maximum shear Green-Lagrangian strain $(\mathrm{mm} / \mathrm{mm})$ predicted by the FE model on different aspects of each articular cartilage structure. Strains on each structure are divided by those occurring throughout the entire thickness of articular cartilage geometry (overall) and those occurring on the contact surface with other knee-joint structures (on contact surface).

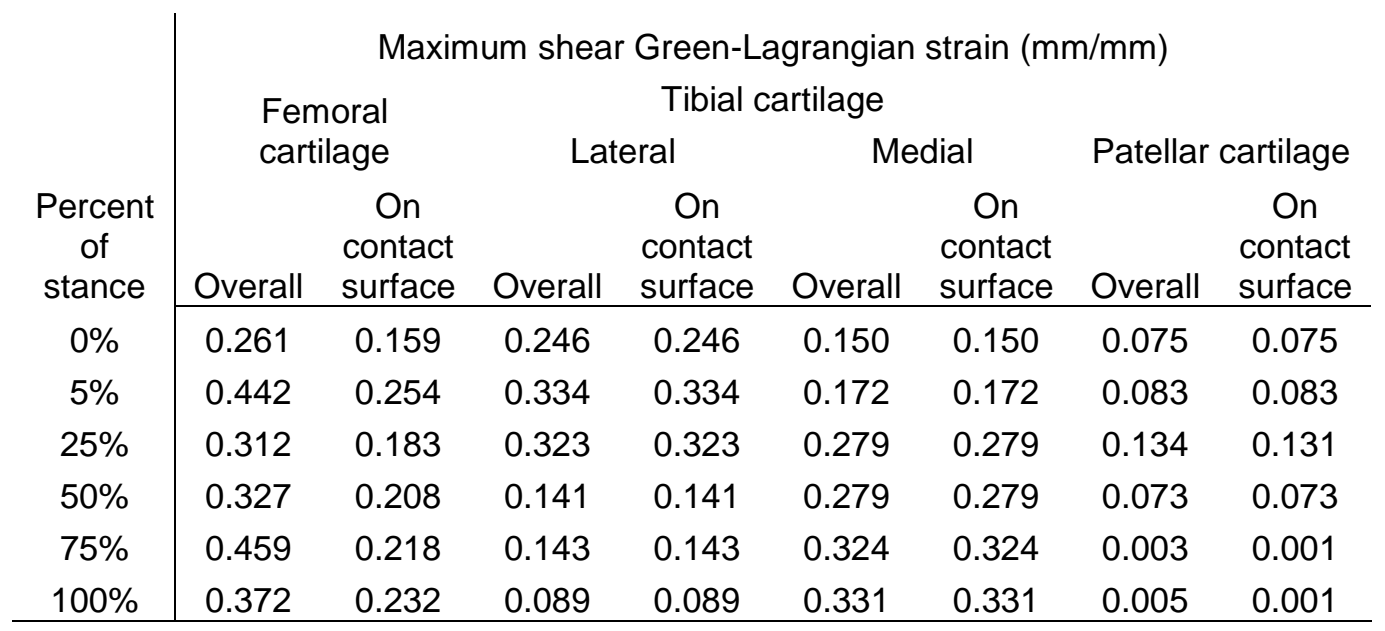


Contact Pressure (MPa)

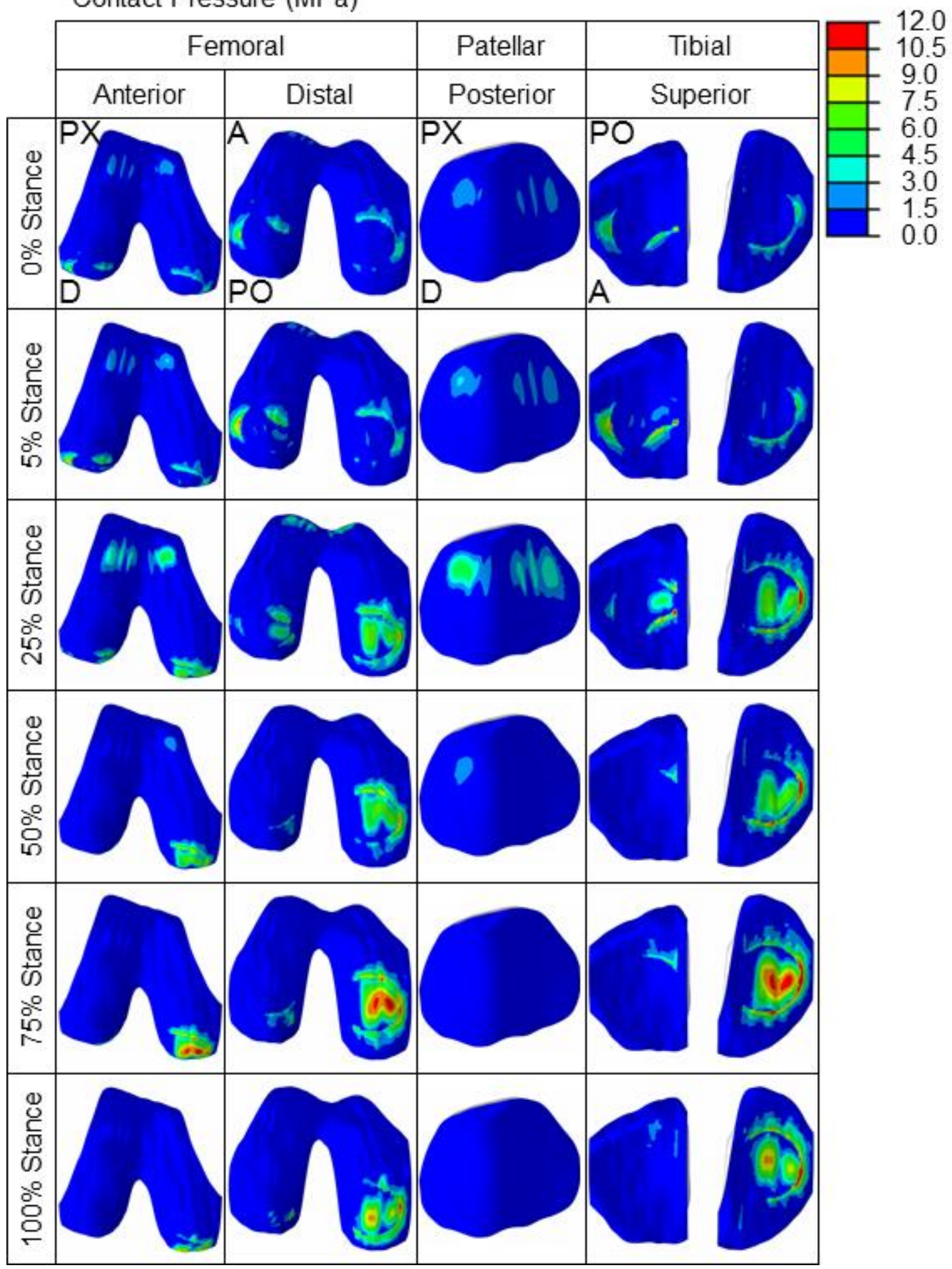

Figure 3.1: Contact pressure on the anterior and distal aspects of the femoral, posterior patellar, and superior lateral (left) and medial tibial (right) cartilages for different loading conditions during the stance phase of gait ( $P X=$ proximal, $\mathrm{D}=$ distal, $\mathrm{A}=$ anterior, and $\mathrm{PO}=$ posterior direction). 
Maximum Green-Lagrangian Shear Strain $(\mathrm{mm} / \mathrm{mm})$

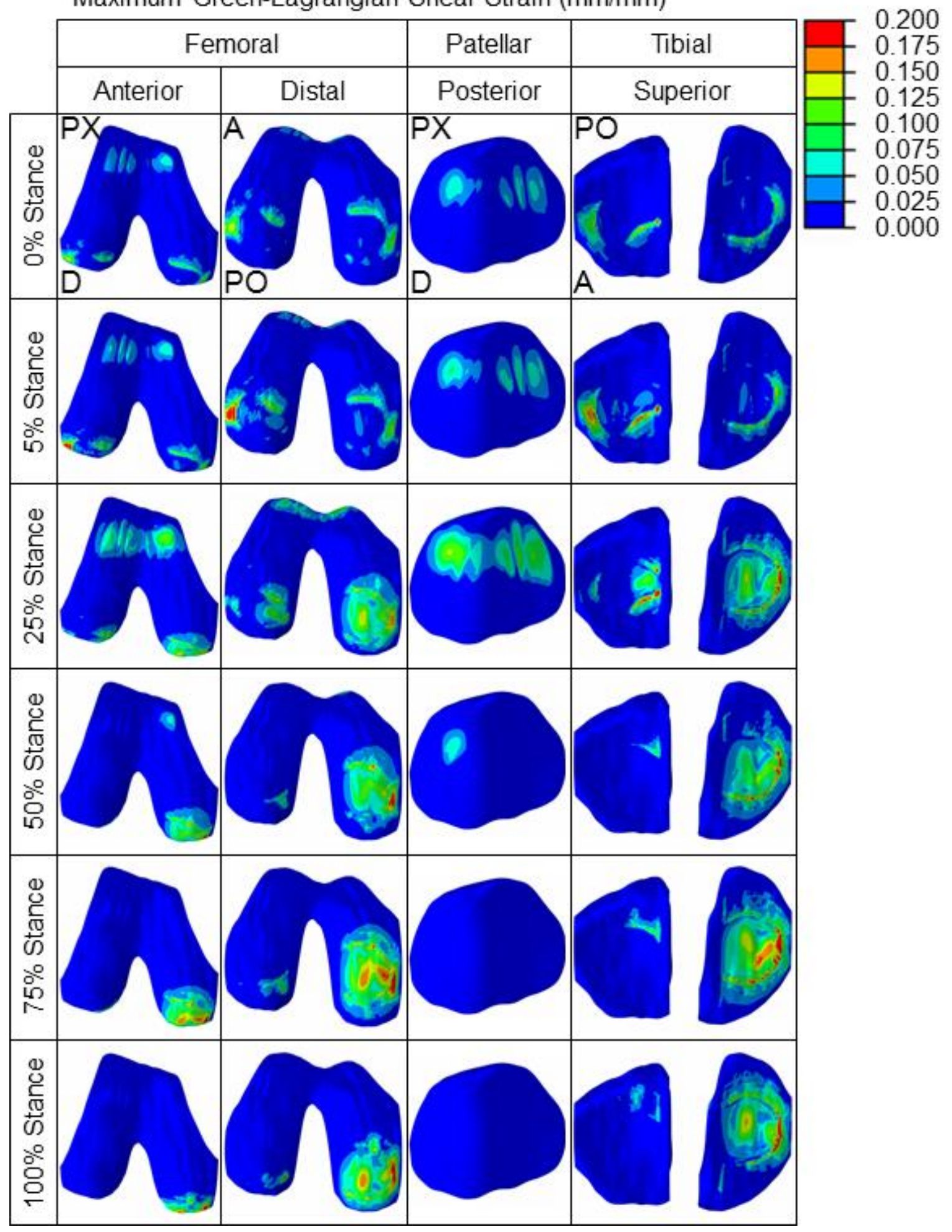

Figure 3.2: Maximum Green-Lagrangian shear strain on the anterior and distal aspects of the femoral, posterior patellar, and superior lateral (left) and medial tibial (right) cartilages for different loading conditions during the stance phase of gait ( $\mathrm{PX}=$ proximal, $\mathrm{D}=$ distal, $\mathrm{A}=$ anterior, and $\mathrm{PO}=$ posterior direction). 
Maximum Principal Green-Lagrangian Strain $(\mathrm{mm} / \mathrm{mm})$

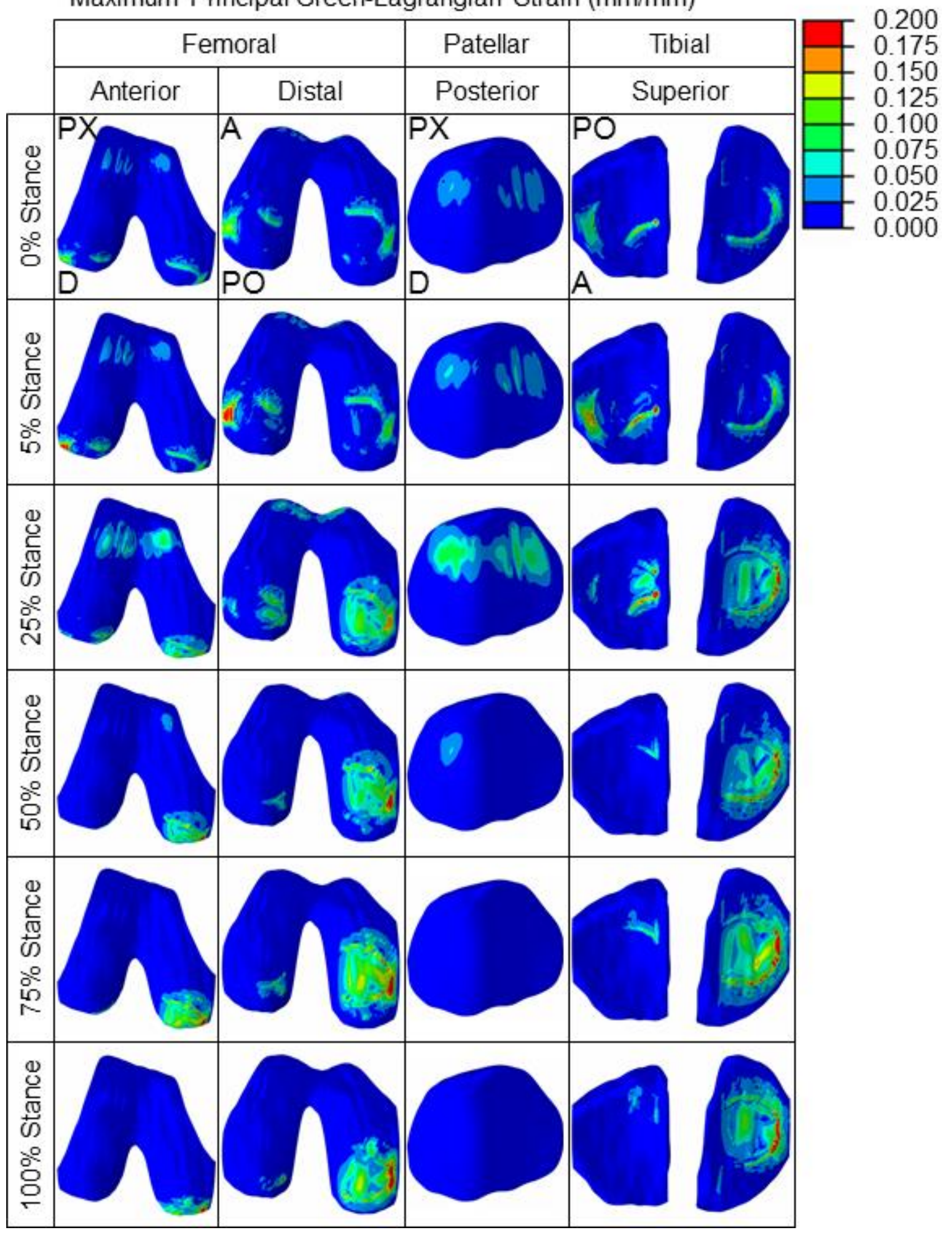

Figure 3.3: Maximum principal Green-Lagrangian strain on the anterior and distal aspects of the femoral, posterior patellar, and superior lateral (left) and medial tibial (right) cartilages for different loading conditions during the stance phase of gait ( $\mathrm{PX}=$ proximal, $\mathrm{D}=$ distal, $\mathrm{A}=$ anterior, and $\mathrm{PO}=$ posterior direction). 


\section{CHAPTER 4}

\section{DISCUSSION}

\subsection{MODEL VALIDATION}

In an effort to validate the FE model, the results displayed in the previous section and in were compared to in-vivo experimental parameters measured during the stance phase of gait for both the tibiofemoral and patellofemoral joints.

\subsubsection{TIBIOFEMORAL JOINT}

Other studies have sought to quantify in vivo tibiofemoral joint contact [60, 61, 62], although only one was found to examine gait motion. Liu, et al. [63] studied tibiofemoral cartilage deformation during the stance phase of gait using MRIs. The group had 8 subjects walk on a treadmill equipped with pressure sensors at a speed of $0.67 \mathrm{~m} / \mathrm{s}$ while their knees were imaged at 30 frames per second over the course of 3 consecutive strides. The tibial and femoral cartilage surfaces were then reproduced from those MRIs in a solid modeling program at $10 \%$ increments of the stance phase of gait. In doing so, the group was able to measure mean contact area and tibial cartilage deformation across all of the subjects for the stance phase of gait [63].

The same general trend is visible between Liu, et al. [63] and this FE model's results for both tibial cartilage deformation contact areas. In both data 
sets, the parameters of interest have two local maxima, falling shortly after heel strike and shortly before toe off. For the Liu, et al. [63] data, peaks occur at $30 \%$ and $80 \%$ of stance, while this FE model's peaks are observed at $5 \%$ and $75 \%$ for cartilage contact area and $25 \%$ and $75 \%$ for maximum tissue minimum principal (compressive) strain. This shows reasonable agreement, especially considering that results from this FE model are only available a select few increments. In addition, Liu et al. show larger magnitudes of both tibial cartilage deformation and contact area occurring throughout the stance phase of gait on the medial side. This also agrees with the results presented in this FE model.

However, contact areas and deformation percentages between the two models are vastly different. Liu, et al. [63] report a maximum tibial cartilage deformation and contact area of approximately $0.23 \mathrm{~mm} / \mathrm{mm}$ and $470 \mathrm{~mm}^{2}$ occurring on the medial tibial cartilage at $30 \%$ of stance. The maximum tibial cartilage contact area observed in the results of this FE model occurred at $75 \%$ of stance on the medial tibial cartilage with a magnitude of $1987.14 \mathrm{~mm}^{2}$. Additionally, the minimum principal (i.e. maximum compressive) strain measured on the medial tibial cartilage occurred at $75 \%$ of stance with a magnitude of $0.289 \mathrm{~mm} / \mathrm{mm}$. While these values don't favorably compare, this may be due to the definitions of these parameters described by Liu, et al. [63]. The group defines cartilage contact area as the area of overlap between the tibia and femur models, and cartilage deformation as the penetration of the cartilage model divided by the thickness of the cartilage at the same location [63]. Thus, that study did not include contributions of the menisci to tibiofemoral contact area or 
cartilage deformation. Contact between the femoral and tibial cartilages was observed and accounted for by this FE model. However, a significant portion of the load transfer between the femoral and tibial cartilages is transmitted through the menisci. Without accounting for this contact, it is understandable that the numbers predicted by this FE model are markedly higher than the tibial cartilage contact areas and deformations measured by Liu, et al. [63].

Additional discrepancy between the results may arise from the different walking speeds examined. Liu, et al. [63] studied patients walking at a constant $0.67 \mathrm{~m} / \mathrm{s}$ on treadmills [63], while the motion capture data for Subject 6 from the Multiple Speed Walking Simulations used in this FE model represents a subject walking at $1.12 \mathrm{~m} / \mathrm{s}$ [51]. The degree to which this discrepancy impacts the results is unknown at this time, but the effects of walking speed on contact area and knee-joint articular cartilage deformation should be examined further in future work with this FE model.

For the reasons outlined above, the FE model and the specific output parameters of interest in the tibiofemoral joint are only partially validated for predicting the proper percent of stance during which peak medial and lateral tibial articular cartilage contact area and minimum principal strain occur, and for qualitatively demonstrating higher magnitude deformations and contact areas on the medial tibial articular cartilage than the lateral tibial articular cartilage throughout the stance phase of gait. Therefore, validation efforts should be ongoing in conjunction with modifications to model complexity. Section 4.3 discusses these changes in more detail. Refer to Table 4.1 for a tabular 
comparison of this FE model's results with Liu, et al. [63] in vivo tibiofemoral joint results.

\subsubsection{PATELLOFEMORAL JOINT}

Similarly to the tibiofemoral joint, other studies have sought to quantify in vivo patellofemoral joint contact [64, 65], although only one was found to examine gait motion. Brechter, et al. [66] sought to quantify changes in patellofemoral contact patterns between subjects with patellofemoral pain and those without. Ten subjects ( 5 men and 5 women) without patellofemoral pain had their knee-joints imaged using an MRI at a variety of static knee flexion angles, and then had their gait cycles recorded with a video motion capture system as they walked over a force plate. Using an inverse dynamics approach, contact variables were then calculated from the observed motion and force plate data, along with the observed overlap of patellar and femoral articular cartilage structures on MRIs [66].

A distinct loss of patellofemoral contact in this FE model was observed for both $75 \%$ and $100 \%$ of stance. Presumably this is due to the selection of patellar tendon material properties, which should clearly be adjusted in future work (refer to Section 4.3.3). As discussed in Section 0, the reported results are for a transversely isotropic patellar tendon with a modulus in the plane of isotropy equal to 0.1 times the elastic modulus in the transverse (stiff) direction. Preliminary studies with this FE model showed further loss of contact with a modulus in the plane of isotropy equal to 1.0 times the transverse modulus, and increased contact with a modulus in the plane of isotropy equal to 0.01 times the 
transverse modulus. This loss of patellofemoral contact makes validation with the Brechter, et al. [66] studies difficult. Regardless, contact pressure and contact area data measured by Brechter, et al. [66] for the patellofemoral joint suggests the same general pattern as the Liu, et al. [63] data for the tibiofemoral joint. Brechter, et al. [66] observed two peaks in their measured contact variables occurring at approximately $20 \%$ and $80 \%$ of stance. Although contact is lost in the latter portion of the stance phase of gait in this FE model, the first peak in both contact pressure and contact area is observable at $25 \%$ of stance. This partial validation presents encouraging evidence for the FE model moving forward.

At $25 \%$ of stance, this FE model predicts a patellofemoral contact area of $1180.48 \mathrm{~mm}^{2}$ and a contact pressure of $5.443 \mathrm{MPa}$. At the same phase of the gait cycle, Brechter, et al. [66] report a contact area of approximately $325 \mathrm{~mm}^{2}$ and a contact pressure of around $3.75 \mathrm{MPa}$. Similarly to the tibiofemoral joint, this FE model appears to over-predict contact variables significantly, presumably caused by inappropriate material properties in the patellar tendon. Thus, the FE model and the specific output parameters of interest in the patellofemoral joint are only partially validated and the comparison should be revisited in future iterations. Refer to Table 4.1 for a tabular comparison of this FE model's results with Brechter, et al. [66] in vivo patellofemoral joint results. 
Table 4.1: Comparison of FE model results with experimental studies; tibiofemoral contact from Liu, et al. [63] and patellofemoral contact in Brechter, et al. [66]. Note: FE model predicted minimum principal (maximum compressive) tibial cartilage strain is compared to maximum tibial cartilage deformation $(\mathrm{mm} / \mathrm{mm})$ from Liu, et al. [63].

\begin{tabular}{|c|c|c|c|c|}
\hline Contact joint & Study & Description of parameter & $\begin{array}{l}\text { Parameter } \\
\text { magnitude }\end{array}$ & $\begin{array}{l}\text { Percent } \\
\text { of stance }\end{array}$ \\
\hline \multirow{4}{*}{$\begin{array}{r}\text { Tibiofemoral } \\
\text { joint }\end{array}$} & Liu, et al. & $\begin{array}{l}\text { Maximum tibial cartilage } \\
\text { deformation }(\mathrm{mm} / \mathrm{mm})\end{array}$ & 0.230 & 0.30 \\
\hline & FE Model & $\begin{array}{l}\text { Minimum principal tibial } \\
\text { cartilage strain }(\mathrm{mm} / \mathrm{mm})\end{array}$ & 0.289 & 0.75 \\
\hline & Liu, et al. & $\begin{array}{r}\text { Maximum tibial cartilage } \\
\text { contact area }\left(\mathrm{mm}^{2}\right)\end{array}$ & 470 & 0.30 \\
\hline & FE Model & $\begin{array}{r}\text { Maximum tibial cartilage } \\
\text { contact area }\left(\mathrm{mm}^{2}\right)\end{array}$ & 1987 & 0.75 \\
\hline \multirow{4}{*}{$\begin{array}{r}\text { Patellofemoral } \\
\text { joint }\end{array}$} & Brechter, et al. & $\begin{array}{r}\text { Patellofemoral contact } \\
\text { area }\left(\mathrm{mm}^{2}\right)\end{array}$ & 325 & 0.25 \\
\hline & FE Model & $\begin{array}{r}\text { Patellofemoral contact } \\
\text { area }\left(\mathrm{mm}^{2}\right)\end{array}$ & 1180 & 0.25 \\
\hline & Brechter, et al. & $\begin{array}{r}\text { Patellofemoral contact } \\
\text { pressure }(\mathrm{MPa})\end{array}$ & 3.75 & 0.25 \\
\hline & FE Model & $\begin{array}{r}\text { Patellofemoral contact } \\
\text { pressure }(\mathrm{MPa})\end{array}$ & 5.443 & 0.25 \\
\hline
\end{tabular}

\subsubsection{VALIDATION IMPLICATIONS}

This FE model appears to predict the timing and locations of maximum contact parameters with reasonable accuracy to experimental studies for the tibiofemoral joint [63] and the patellofemoral joint [66]. This suggests that the model geometry and kinematic boundary conditions utilized in this FE model are appropriate and desirable. The fact that the absolute values of contact area, contact pressure, and minimum principal strain measured in the tibiofemoral and patellofemoral joint do not match experimental studies points to limitations in the material properties used, as well as potentially the loading boundary conditions. 
Possible changes in these areas and additional validation studies are discussed in Section 4.3, and should be considered in future work with this FE model.

\subsection{FE STUDY AGREEMENT}

Although complete model validation was not achieved for either the tibiofemoral or patellofemoral joints, it is still desirable to compare the contact and strain parameters output by this FE model to other FE studies of the kneejoint and gait. At the very least, these other studies offer an opportunity to examine model parameters in future work.

Adouni, et al. have published multiple simulations investigating knee-joint mechanics during the gait cycle $[38,67]$. These utilize significantly more complex material models and loading conditions with more simplistic knee-joint component geometries (e.g. representing ligament structures with onedimensional spring elements), but examine the same time points of the stance phase of gait as this FE model. From a holistic comparison of results, tibiofemoral contact area and tibial contact pressures have the same order of magnitude between studies. Across all comparable variables (tibiofemoral and patellofemoral contact areas, tibial contact pressure, and maximum principal strain), this FE model predicts higher values than Adouni, et al. [38,67]. For $25 \%$ and $75 \%$ of stance, Adouni, et al. $[38,67]$ predicts maximum contact pressures of 8.1 and $7.5 \mathrm{MPa}$ respectively, as well as maximum principal strains of 0.20 and 0.087 on the superficial tibial cartilage layer. The FE model used in this thesis predicts maximum contact pressures of 15.491 and $16.036 \mathrm{MPa}$ for 
$25 \%$ and $75 \%$ of stance respectively, as well as maximum principal strains of 0.705 and 0.142 on the contacting surface elements of the tibial cartilage.

Yang, et al. have also examined cartilage contact patterns in the human knee-joint during the stance phase of gait using FE analysis [68]. This group shows a maximum normal stress of approximately 12,10 , and $9.5 \mathrm{MPa}$ in the medial tibial cartilage for $25 \%, 50 \%$, and $75 \%$ of stance for a subject with normal gait patterns. Additionally, they report a maximum normal stress of approximately 2, 9, and $8 \mathrm{MPa}$ in the lateral tibial cartilage for $25 \%, 50 \%$, and $75 \%$ of stance for a subject with normal gait patterns. This thesis' FE model predicts maximum contact pressures of $13.993,14.610$, and $16.036 \mathrm{MPa}$ for the medial tibial cartilage and $15.491,4.568$, and $5.071 \mathrm{MPa}$ for lateral tibial cartilage, each for $25 \%, 50 \%$ and $75 \%$ of stance respectively.

Table 4.2: Comparison of FE model results with other FE studies: Adouni, et al. $[38,67]$ and Yang, et al. [68].

\begin{tabular}{rr|ccc|} 
& Percent of stance & $25 \%$ & $50 \%$ & $75 \%$ \\
\hline & Adouni, et al. & 8.1 & - & 7.5 \\
Maximum contact pressure, & Yang, et al. (medial) & 12.0 & 10.0 & 9.5 \\
superficial tibial cartilage layer (MPa) & FE Model (medial) & 13.9 & 14.6 & 16.0 \\
& Yang, et al. (lateral) & 2.0 & 9.0 & 8.0 \\
& FE Model (lateral) & 15.5 & 4.6 & 5.1 \\
\hline Maximum principal strain, superficial & Adouni, et al. & 0.200 & - & 0.087 \\
tibial cartilage layer $(\mathrm{mm} / \mathrm{mm})$ & FE Model & 0.705 & 0.310 & 0.142
\end{tabular}

These comparisons point to several useful conclusions about the FE model used in this thesis. First and foremost, stress concentrations occurring on the femoral and tibial cartilages seem to lead to vast over-predictions of 
maximum contact parameters as well as tissue strains within each structure. This area should be among the first examined in future work. Alleviating stress concentrations could directly lead to more comparable results with other FE studies as well as in vivo measurements. Next, this FE model appears to correctly capture the effect of transferring primary contact in the tibiofemoral joint from the lateral to medial articular surfaces from $0 \%$ of stance to $25 \%$ and through toe-off. However, as the results in Chapter 3 will corroborate, this effect is over-estimated in that lateral tibial contact is almost completely removed in the later portions of the stance phase. This, among other over-predictions in patellofemoral and tibiofemoral contact, is presumably due to inappropriate material properties assigned to structures within the model. This contact transfer might be better estimated if, for example, the stabilizing ligaments and tendons crossing the joint were reformulated to prevent excessive relative motion between the femur and tibia. These improvements to the model and more are discussed in the following section.

\subsection{FUTURE WORK}

This model represents a significant step forward towards the long term goals of this project. With the improvements outlined in this section, this FE model can achieve improved accuracy for gait simulations, as well as predict articular cartilage stress and strains in other exercises, especially for individuals suffering from obesity, suffering from an $\mathrm{OC}$ defect, or recovering from $\mathrm{OC}$ surgery. 


\subsubsection{VALIDATION SIMULATIONS}

Discussed in Section 4.1.3, this FE model appears to predict the timing and locations of maximum contact parameters with reasonable accuracy to in vivo experimental studies, but appears to over-estimate the absolute values of contact area, contact pressure, and minimum principal strain measured in both the tibiofemoral and patellofemoral joint. However, as discussed earlier, both of the primary in vivo experimental studies used for comparison to this FE model include a large digital or computational component, which leads to some inherent limitations for validation efforts. As such, perhaps the first consideration for continued work with this FE model is additional simulations for comparison with more rigorous, in vitro experimental studies of the knee-joint.

Numerous in situ or in vitro experimental studies have sought to quantify tibiofemoral joint contact $[62,69,70]$ and patellofemoral joint contact $[62,71,72$, $73,74]$ variables, including in attempts to simulate gait [75]. These experimental studies are more rigorous than the in vivo studies discussed in Section 4.1 in that they measure contact pressure and contact area directly by use of pressuresensitive films or load cells, without relying heavily on additional calculations or estimation techniques. However, by virtue of being in vitro studies, these experiments use cadaveric specimens and cannot, therefore, serve as total validation of this FE model. Still, comparisons to these studies could provide additional authentication of model prediction accuracy, or point to other areas for improvement in future work. Thus, in subsequent simulations, the FE model 
should be modified to replicate the loading and boundary conditions represented in each of these in vitro studies and the results should be compared on an individual basis. This process could serve to either enhance confidence in the model results beyond the in vivo comparisons made in this thesis, or could highlight specific areas of the model to target for improvement.

\subsubsection{EXPANDED SIMULATIONS WITH OPENSIM MUSCLE FORCES}

Discussed briefly in Section 1.3, the FE model developed in this thesis will be used in future studies with a motion analysis system in order to produce subject-specific analysis of walking, elliptical training, and stationary bicycle training for clinically relevant studies aimed at prevention, treatment, and rehabilitation of $\mathrm{OC}$ injuries.

First and foremost, this will require reformulating the loads and boundary conditions imposed on the FE model to reflect these different exercises. OpenSim offers an extremely unique opportunity to include subject- and exercise-specific loads developed from marker data captured experimentally. Following the work-flow presented in Figure 4.1, a three-dimensional motion capture system will record the positions of body segments throughout an exercise while load cells record the ground reaction forces and moments, which will then be imported into OpenSim for analysis. The ID Tool will be used to convert the experimental data into accelerations of the mass centers of each body segment, and equivalent joint contact forces and moments required to produce that motion. Finally, the SO Tool is used to find an optimized representation of that joint contact as numerous muscle forces crossing the joint. 
Here, instead of running JRA to obtain joint reaction forces and moments (including muscle activations) to be applied at the rigid body reference node of the femur in the FE model, the muscle forces vectors would be applied directly to their appropriate points of attachment within the FE model. This type of loading within the FE model would not only more accurately represent the conditions present anatomically (and therefore presumably approach a more accurate solution), but also provide better localized predictions of stress and strain within bone tissue if a non-rigid material model was included (discussed more in Section 4.3.3).
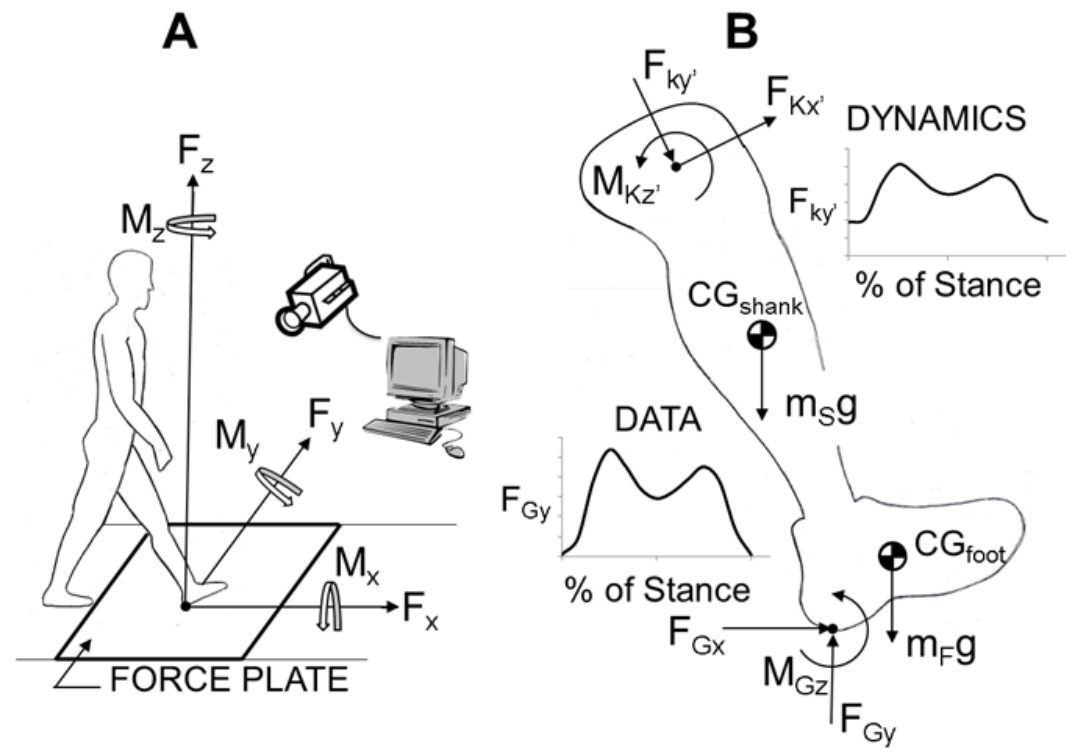

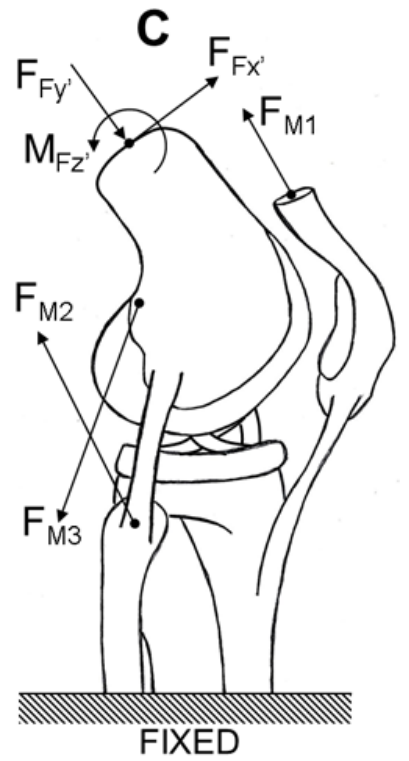

FIXED

Figure 4.1: Three-dimensional motion analysis work-flow. (A) A motion capture system records the positions of experimental markers on a subject performing a specific exercise while force plates measure forces and moments. (B) The ID Tool in OpenSim is used to calculate equivalent joint contact forces and moments at the knee-joint required to produce the experimentally observed motion. (C) OpenSim's SO Tool is used to obtain individual muscle force vectors and consequently, the resultant joint contact force that can be applied as loads in the future FE model. 
Additionally, an advantage of producing model inputs directly, as opposed to obtaining them from outside sources such as OpenSim's Gait 2392 model, is more direct control over the time period studied. There is significant evidence in viewing the motion presented by Gait 2392 that the subject does not in actuality completely reach toe-off before the data collection period ends. If this is indeed the case, all of the results from this model have been shifted with respect to their reported percent of stance, i.e. the results shown for $25 \%$ of stance may truly represent $20 \%$ of stance, and $100 \%$ of stance may actually be consistent with loading from $90 \%$ of stance. It is not directly clear if this change alone makes this FE model's timing of peak contact parameters match experimental studies better or worse, due to the different periods of the stance phase being studied (i.e. Liu, et al. [63] observe at $10 \%$ increments of stance and this FE model studies $0 \%, 5 \%, 25 \%, 50 \%, 75 \%$, and $100 \%$ of stance). Regardless, future work with an in-house motion capture system to produce model input loads for controlled motion periods is further desirable to ensure comparability with results from other studies.

\subsubsection{MATERIAL PROPERTIES}

In many cases, the material properties utilized in this study have been simplified to the most basic linear elastic isotropic models available. Changing each structure's properties to more closely resemble the physiological mechanics could greatly improve model accuracy. These changes can be made either with Abaqus' built-in more sophisticate material formulations, or through the implementation of UMATs. 
Anatomically, bone is composed of a hard cortical shell and a highly heterogeneous, softer trabecular center [44]. Human cortical bone is generally assumed to be transversely anisotropic, and exhibits viscoelasticity, increasing its modulus and strength with increases to the loading rate [44]. For static compressive loading, previous FE studies have shown that changing cortical bone material properties from linear elastic orthotropic to completely rigid affected contact variables by less than $2 \%$ [35]. However, for studies using loading conditions corresponding to stair climbing and walking, the rigid bone assumption was shown to produce much larger contact pressures and contact areas in hip joint cartilage than more sophisticated material models $[76,77]$. Thus, for the expanded simulations sought for this FE model (including more physically relevant, dynamic loads), increasing the complexity of cortical bone material properties may reduce the inflated contact pressure and contact areas predicted by this FE model in the knee-joint articular cartilage, and therefore improve solution accuracy. Thus, it is desirable to produce more sophisticated models of the cortical shell, as well as trabecular bone, and perform a parametric study to determine whether or not the rigid assumption used in this model is truly valid moving forward.

Mentioned earlier, articular cartilage is often mathematically modeled as a biphasic, fibril-reinforced composite [37]. This approach hopes to capture the anisotropic, poroelastic qualities of the tissue, which has depth-dependent material properties that vary highly due to alignment of collagen and proteoglycans, as well as water content in the superficial, transitional, and deep 
zones [44]. In order to better predict localized stress and strain within the tissue, numerous FE studies have imposed more complex material properties, including nearly incompressible Mooney-Rivlin [29], [30], hyperelastic depth-dependent nonfibrillar matrix and continuum/membrane fibrils [37], [78], [79], and heterogeneous fibril-reinforced poroviscoelastic [80]. These should be evaluated on an individual basis and considered for inclusion in this FE model by way of Abaqus UMATs in future work to improve accuracy of predicted solutions for articular cartilage.

The lateral and medial menisci are also anisotropic, viscoelastic tissues, like articular cartilage [39]. Thus for modeled exercises with longer loading times, it may prove desirable to implement more complicated material models in these structures, as well. Previous FE models have implemented a variety of material formulations to best capture the conforming functionality of the menisci, including material properties such as linear elastic transversely isotropic [80], Fung orthotropic hyperelastic [29], [30], and even anisotropic with depthdependent collagen reinforcement [37], [78], [79]. Again, each of these should be evaluated and possibly included in future iterations of this FE model using UMATs.

Finally, ligament and tendon structures should have their material properties adjusted in future studies. It is highly possible that using linear elastic isotropic properties for stabilizing ligaments around the knee-joint in this FE model add non-anatomically accurate stiffness to the joint, and impact the predicted articular cartilage stress and strain values. Also, the discussion in 
Chapter 4 indicates that the selection of patellar tendon material constants may have directly lead to a loss of contact in the patellofemoral joint at $75 \%$ and $100 \%$ of stance. As discussed in Section 0, ligaments and tendons both exhibit nonlinear anisotropic material properties [44]. Furthermore, properties are highly dependent on anatomical site, subject age, tissue disease state, and loading rate [44]. For this reason, future investigations with this FE model should implement different properties for each ligament and tendon structure, taking into consideration important factors such as subject age and loading conditions applied within the model. Numerous FE studies have utilized a variety of approaches to capture the nonlinear anisotropic nature of ligaments and tendons, including modeling these structures as one-dimensional nonlinear spring elements [35], [46], [36], [68] or with transversely isotropic hyperelastic properties [29], [30], [32], [81]. Since ligament and tendon mesh geometry is already modeled in this FE model, the transversely isotropic hyperelastic model seems to be an appropriate choice for future work.

\subsubsection{MENSICAL ATTACHMENTS}

In addition to the proposed adjustments to tissue material properties, it is also desirable to change the attachment method used to hold the lateral and medial meniscus in place. The boundary conditions used to anchor the menisci create artificial stiffness and lead to stress concentrations in the femoral and tibial cartilages (as shown in Chapter 4). Previous FE studies have sought to mitigate this problem by modeling the meniscal horn attachments to the tibia using linear spring elements [29] , [30], [35], [46], [55]. This approach may lead to a more 
conclusive convergence study, and should be investigated further in attempts to increase solution accuracy by removing stress concentrations from artificial stiffness in the meniscal horns.

\subsubsection{INVESTIGATION OF OC DEFECTS}

A major future goal for this FE model is to identify and recommend exercises that may slow the progression of $O C$ tissue damage in individuals with minor asymptomatic OC defects being treated conservatively, and/or facilitate treatment and rehabilitation of individuals treated with surgical interventions. To that end, future work with this FE model could include purposefully introducing defects in the geometry of articular cartilage structures or intentionally weakening the material properties in areas of interest for comparison with healthy tissues, as done in several previous FE analyses [37, 80, 81, 82]. This work, coupled with updated loads and boundary conditions for different exercises, could help quantify the changes to localized stress and strain on articular cartilage surfaces between defected and healthy tissues, leading to a quantitative basis for clinical recommendation of rehabilitation exercises.

\subsubsection{ADDITIONAL GEOMETRY}

The Open Knee project, from which model geometry for this FE model was acquired, also includes updated knee-joint structures which could affect model variable predictions. These "Generation 2" components include the fibula, a complete LCL (which attaches to the fibula), proximal and distal tibial MCL attachments (updated from the single attachment in the current FE model), and meniscal horns for both the lateral and medial menisci. These structures are 
currently being worked on by the Open Knee group, and therefore would require some additional processing in a solid modeling program, such as SolidWorks, before they could be appropriately utilized in a future version of this FE model. However, the complete "Generation 2" parts could be adopted directly, if finished in the near future. Regardless of approach, implementing these new geometric features represents another possible area where the accuracy of the FE model could be significantly improved.

\subsubsection{DAMPING STABILIZATION FACTOR CONVERGENCE STUDY}

Discussed briefly in Section 2.2.7, the damping stabilization factors used to achieve model convergence in this FE model need to be fully examined in future work. While it was demonstrated that ratio of viscous forces to total forces within the model was kept below $10 \%$ in all cases, it is unclear from the Abaqus documentation if the observed ratio shows that artificial viscous forces truly don't dominate the model. If possible, total model energy should be compared to energy dissipated by viscous forces for a more complete picture of the damping stabilization factor's influence in the model. Additionally, a damping stabilization factor convergence study is therefore imperative to demonstrate that the selected factors do not affect the results within a reasonable tolerance.

\subsubsection{REFORMULATION OF MESH BLOCK INTERFACES}

When viewing results of this FE model and preparing them for display in Chapter 3, it became apparent that some problems may have occurred in merging boundaries of the mesh blocks in TrueGrid, before the parts were implemented in Abaqus. Before writing the TrueGrid mesh file to an extension 
that can be imported into Abaqus, a merge command is required to combine nodes occupying similar positions in space. For example, if two edges of the computational block are projected onto the same three-dimensional curve, the nodes on each edge that coincide need to be merged together to make a continuous mesh. However, discontinuities in the mesh appear to persist when the meshes are viewed with "free edges" visible in Abaqus. Figure 4.2 shows some of these discontinuities on the femoral cartilage. The fact that these edges present themselves in this view indicate that the merge tolerance used in the final TrueGrid step before importing part files into Abaqus is too fine. If nodes that should be merged are further away from each other than the specified tolerance, then the elements lose connectivity in these areas and the free edges like those shown in Figure 4.2 present themselves. Fortunately, the areas that these discontinuities occurred seem to be away from the areas of interest on articular cartilage tissues. Still, these areas need to be located and remedied immediately in future studies so that results are not unintentionally affected. 


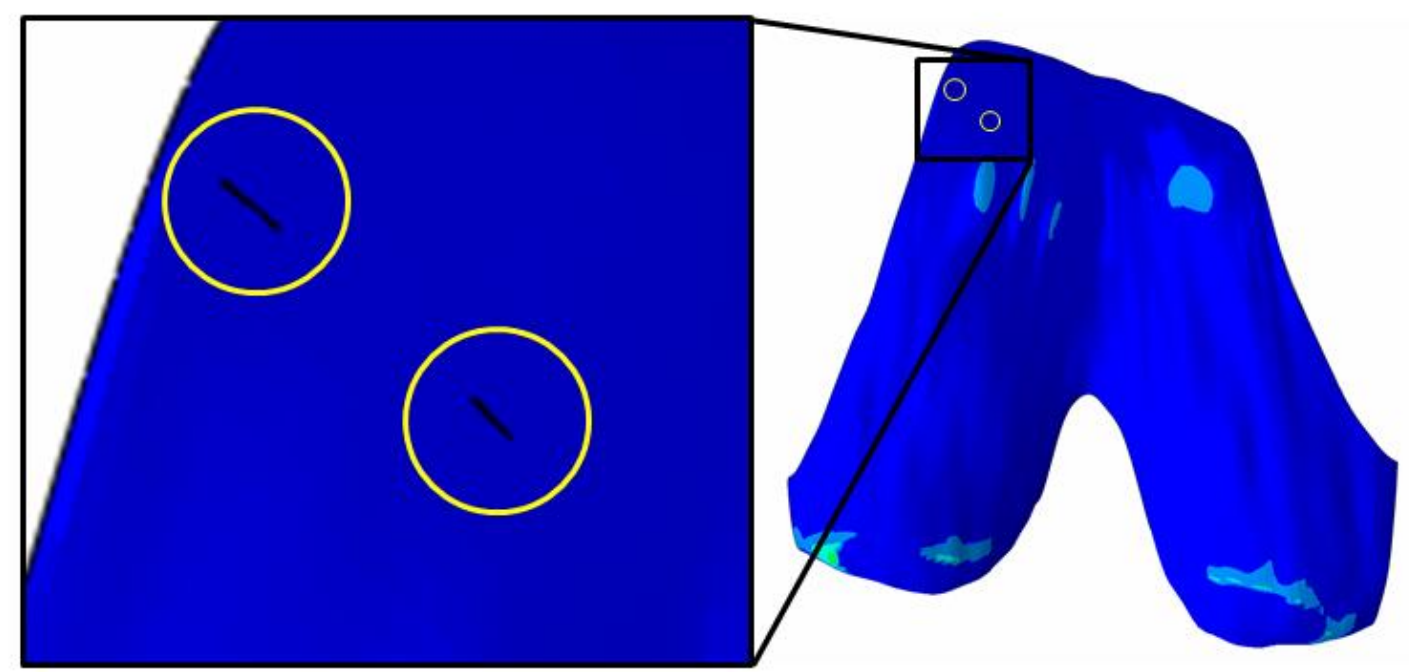

Figure 4.2: "Free edges" view of meshed parts in Abaqus reveals unintended edges, most likely resulting from an overly fine mesh merging tolerance specified in TrueGrid.

\subsubsection{CARTILAGE MATRIX DAMAGE AND CHONDROCYTE APOPTOSIS}

Articular cartilage contains specialized cells called chondrocytes, which regulate biochemical balance and give structural integrity to the tissue [44]. Active cell death in response to biochemical stimuli, or apoptosis, has been shown to be the predominant mode of cell death in patients with OA [83]. Experimental studies applying mechanical loading to articular cartilage in vitro show that there is a strong positive association between cartilage matrix damage and chondrocyte apoptosis [84], indicating that prolonged or large magnitude impact loading causing tissue damage also leads to cell death $[56,59,85,86$, $87,88,89]$.

Threshold stresses and strains for cartilage matrix damage and cell death are shown to be dependent on rate of loading [56, 59, 86, 87], duration of load 
[85, 89], and magnitude of load [56, 59, 85, 88, 89]. However, maximum shear strain has been identified as one major failure mode for the cartilage matrix [57, 58]. Cartilage apoptosis has been observed when specimens were subject to $2 \%, 5 \%$, and $10 \%$ shear strains for 6 hours, and at $10 \%$ shear strain after only 2 hours [89]. Shear strain was also observed to cause cartilage matrix damage and chondrocyte apoptosis above $25 \%$ strain at a rate of $500 /$ second [56]. Another study at this strain rate (500/s) showed that cartilage cell death occurred at compressive stresses of 20 or $30 \mathrm{MPa}$, corresponding to $20 \%$ strain [87].

One study that sought to quantify the threshold levels of strain rate and peak stress at which sub-impact loads could induce cartilage matrix damage or chondrocyte apoptosis [59]. Results confirmed that visible matrix cracks resulting from compressive stresses were associated with cell apoptosis [59]. Strain rates between $0.3 / \mathrm{s}$ and $0.7 / \mathrm{s}$ produced visible matrix damage as well as cell deactivation of greatest severity in the superficial zone of the cartilage, while lower strain rates $\left(3 \times 10^{-5} / \mathrm{s}\right)$ resulted in cell deactivation throughout the cartilage depth, but leaving no visible damage [59].

Since cartilage matrix damage and chondrocyte apoptosis are so closely related, and no studies have been found that properly define threshold values for each (separate of the other), comparisons with this FE model's results should be approached with caution. Further work to quantify the strain rates and compressive strains normal to the articular cartilage surface should be conducted before any evaluation is made. Since the current model focuses on quantifying every day cartilage loads present during the stance phase of gait, cartilage matrix 
damage or significant chondrocyte apoptosis is not suspected to occur. However, results from expanded simulations with this FE model (such as those including OC defects or OA models) should be compared on an individual basis to each study discussed above to determine if chondrocyte apoptosis or cartilage matrix damage could be an issue. 


\section{CHAPTER 5}

\section{CONCLUSION}

The specific objectives of this thesis project were to (1) generate a detailed total knee-joint FE model for predicting OC tissue stress and strain during gait and to (2) validate that FE model with published data from in vivo studies of gait. The first objective was reasonably accomplished, as this total knee-joint FE model represents a useful foundation for expansion in future work. With regards to the second objective, partial validation with in vivo experimental studies was achieved for the timing during the stance phase and locations of maximum contact parameters with reasonable accuracy to for the tibiofemoral joint and the patellofemoral joint. This suggests that the model geometry and kinematic boundary conditions utilized in this FE model are appropriate and desirable, but since the absolute values of contact area, contact pressure, and minimum principal strain measured in the tibiofemoral and patellofemoral joint do not match experimental studies, limitations in the material properties used, as well as potentially the loading boundary conditions represent primary areas for improvement.

The long-term goal of this project is to use subject-specific, total knee-joint FE models in future studies with a motion analysis system in order to produce 
subject-specific analysis of walking, elliptical training, and stationary bicycle training for clinically relevant studies aimed at prevention, treatment, and rehabilitation of OC injuries. Given the progress made with this model, prospective improvements (such as varying material properties, defining physiologically accurate meniscal attachment methods, including additional geometry, performing a damping stabilization factor convergence study, and reformulating mesh block interfaces) allow these goals to seem attainable with continued work. 


\section{BIBLIOGRAPHY}

[1] J. Buckwalter and H. Mankin, "Articular cartilage. Part I: tissue design and chondrocyte-matrix interactions," The Journal of Bone and Joint Surgery, Vols. 79-A, no. 4, pp. 600-611, 1997.

[2] J. Buckwalter and H. Mankin, "Articular cartilage. Part II: degeneration and osteoarthritis, repair, regeneration, and transplantation," The Journal of Bone and Joint Surgery, Vols. 79-A, no. 4, pp. 612-632, 1997.

[3] E. Yelin, L. Murphy, M. Cisternas, A. Foreman, D. Pasta and C. Helmick, "Medical care expenditures and earnings losses among persons with arthritis and other rheumatic conditions in 2003 , and comparisons with 1997," Arthritis and Rheumatism, vol. 56, no. 5, pp. 1397-1407, 2007.

[4] C. Cooper, S. Snow, T. McAlindon, S. Kellingray, B. Stuart, D. Coggon and P. Dieppe, "Risk factors for the incidence and progression of radiographic knee osteoarthritis," Arthritis \& Rheumatism, vol. 43, no. 5, pp. 9951000, 2000.

[5] K. Flegal, M. Carroll, C. Ogden and L. Curtin, "Prevalence and trends in obesity among US adults, 1999-2008.," Journal of the American Medical 
Association, vol. 303, no. 3, pp. 235-241, 2010.

[6] C. Ogden, S. Yanovski, M. Carroll and K. Flegal, "The epidemiology of obesity," Gastroenterology, vol. 132, no. 6, p. 2087, 2007.

[7] E. Finkelstein, J. Trogdon, J. Cohen and W. Dietz, "Annual medical spending attributable to obesity: payer- and service-specific estimates," Health Affairs, vol. 28, no. 5, pp. 822-831, 2009.

[8] Y. Wang, M. Beydoun, L. Liang, B. Caballero and S. Kumanyika, "Will all Americans become overweight or obese? Estimating the progression and cost of the US obesity epidemic," Obesity, vol. 16, no. 10, pp. 23232330, 2008.

[9] W. Haskell, I. Lee, R. Pate, K. Powell, S. Blair, B. Franklin, C. Macera, G. Health, P. Thompson and A. Bauman, "Physical activity and public health: updated recommendation of adults from the American College of Sports Medicine and the American Heart Association," Medicine and Science in Sports and Exercise, vol. 39, no. 8, p. 1423, 2007.

[10] G. Deyle, N. Henderson, R. Matekel, M. Ryder, M. Garber and S. Allison, "Effectiveness of manual physical therapy and exercise in osteoarthritis of the knee," Annals of Internal Medicine, vol. 132, no. 3, pp. 173-181, 2000.

[11] T. Andriacchi and A. Mundermann, "The role of ambulatory mechanics in the 
initiation and progression of knee osteoarthritis," Current Opinion in Rheumatology, vol. 18, no. 5, pp. 514-518, 2006.

[12] R. Browning and R. Kram, "Effects of obesity on the biomechanics of walking at different speeds," Medicine and Science in Sports and Exercise, vol. 39, no. 9, p. 1632, 2007.

[13] S. Messier, "Osteoarthritis of the knee and associated factors of age and obesity: effects on gait," Medicine and Science in Sports and Exercise, vol. 26, no. 12, p. 1446, 1994.

[14] S. Messier, D. Gutekunst, C. Davis and P. DeVita, "Weight loss reduces kneejoint loads in overweight and obese older adults with knee osteoarthritis," Arthritis \& Rheumatism, vol. 52, no. 7, pp. 2026-2032, 2005.

[15] L. Sharma, C. Lou, S. Cahue and D. Dunlop, "The mechanism of the effect of obesity in knee osteoarthritis: the mediating role of malalignment," Arthritis \& Rheumatism, vol. 43, no. 3, pp. 568-575, 2001.

[16] S. Issa and L. Sharma, "Epidemiology of osteoarthritis: an update," Current Rheumatology Reports, vol. 8, pp. 7-15, 2006.

[17] P. DeVita and T. Hortobagyi, "Obesity is not associated with increased knee joint torque and power during level walking," Journal of Biomechanics, vol. 36, no. 9, pp. 1355-1362, 2003. 
[18] K. Kaufman, C. Hughes, B. Morrey, M. Morrey and K. An, "Gait characteristics of patients with knee osteoarthritis," Journal of Biomechanics, vol. 34, no. 7, pp. 907-915, 2001.

[19] A. Perillo-Marcone and M. Taylor, "Effect of varus/valgus malalignment on bone strains in the proximal tibia after TKR: an explicit finite element study," Journal of Biomechanical Engineering, vol. 129, no. 1, pp. 1-11, 2007.

[20] T. Boyd, R. Neptune and M. Hull, "Pedal and knee loads using a multi-degreeof-freedom pedal platform in cycling," Journal of Biomechanics, vol. 30, no. 5, pp. 505-511, 1997.

[21] M. Ericson, "On the biomechanics of cycling. A study of joint and muscle load during exercise on the bicycle ergometer," Scand J Rehabil Med Suppl, vol. 16, pp. 1-43, 1986.

[22] C. Gregersen and M. Hull, "Non-driving intersegmental knee moments in cycling computed using a model that includes three-dimensional kniematics of the shank/foot and the effect of simplifying assumptions," Journal of Biomechanics, vol. 36, no. 6, pp. 803-813, 2003.

[23] K. Knutzen, W. McLaughlin, A. Lawson, B. Row and L. Martin, "Influence of ramp position on joint biomechanics during elliptical trainer exercise," Open Sports Sciences Journal, vol. 3, pp. 165-177, 2010. 
[24] S. Lou, Y. Chen, C. Chen, J. You and C. Hsu, "Functional evaluation of elliptical trainer with human motion analysis," Journal of Biomechanics, vol. 40, no. 2, p. 329, 2007.

[25] T. Lu, H. Chien and H. Chen, "Joint loading in the lower extremities during elliptical exercise," Medicine and Science in Sports and Exercise, vol. 39, no. 9, p. 1651, 2007.

[26] J. Wolchok, M. Hull and S. Howell, "The effect of intersegmental knee moments on patellofemoral contact mechanics in cycling," Journal of Biomechanics, vol. 31, no. 8, pp. 677-683, 1998.

[27] D. D'Lima, N. Steklov, S. Patil and C. Colwell, "The Mark Coventry Award: in vivo knee forces during recreation and exercise after knee arthroplasty," Clinical Orthopaedics and Related Research, vol. 466, no. 11, pp. 2605$2611,2008$.

[28] A. Valkeapaa, A. Klodowski, T. Rantalainen and A. Mikkola, "Knee cartilage surface loading during stationary bicycling," Computer Methods in Mechanics, 2011.

[29] A. Erdemir and S. Sibole, "Open Knee: A three-dimensional finite element representation of the knee joint, User's Guide, Version 1.0.0," 2010.

[30] S. Sibole, C. Bennetts, S. Maas, A. van den Bogert, J. Weiss and A. Erdemir, "Open knee: a 3d finite element representation of the knee joint," in 34th 
Annual Meeting of the American Society of Biomechanics, 2010.

[31] "About BMI for Adults," Centers for Disease Control and Prevention, 13 $\begin{array}{llll}\text { September } & 2011 . & \text { [Online]. Available: }\end{array}$ http://www.cdc.gov/healthyweight/assessing/bmi/adult_bmi/index.html. [Accessed 5 December 2013].

[32] E. Pena, B. Calvo, M. Martinez and M. Doblare, "A three-dimensional finite element analysis of the combined behavior of ligaments and menisci in the healthy human knee joint," Journal of Biomechanics, vol. 39, no. 9, pp. 1686-1701, 2006.

[33] G. Li, O. Lopez and H. Rubash, "Variability of a three-dimensional finite element model constructed using magnetic resonance images of a knee for joint contact stress analysis," Journal of Biomechanical Engineering, vol. 123, pp. 341-346, 2001.

[34] M. Bendjaballah, A. Shirazi-Adl and D. Zukor, "Biomechanics of the human knee joint in compression: reconstruction, mesh generation, and finite element analysis," The Knee, vol. 2, no. 2, pp. 69-79, 1995.

[35] T. Haut-Donahue and M. Hull, "A finite element model of the human knee joint for the study of tibio-femoral contact," Journal of Biomechanical Engineering, vol. 124, p. 273, 2002.

[36] N. Yang, P. Canavan, H. Nayeb-Hashemi, B. Najafi and A. Vaziri, "Protocal for 
constructing subject-specific biomechanical models of knee joint," Computer Methods in Biomechanics and Biomedical Engineering, vol. 13, no. 5, pp. 589-603, 2010.

[37] R. Shirazi and A. Shirazi-Adl, "Computational biomechanics of articular cartilage of human knee joint: effect of osteochondral defects," Journal of Biomechanics, vol. 42, no. 15, pp. 2458-2465, 2009.

[38] M. Adouni and A. Shirazi-Adl, "Consideration of equilibrium equations at the huip joint alongside those at the knee and ankle joints has mixed effects on knee joint response during gait," Journal of Biomechanics, 2012.

[39] Y. Guo, X. Zhang and W. Chen, "Three-dimensional finite element simulation of total knee joint in gait cycle," Acta Mechanica Solida Sinica, vol. 22, no. 4, pp. 347-351, 2009.

[40] C. Armstrong, W. Lai and V. Mow, "An analysis of the unconfined compression of articular cartilage," Journal of Biomechanical Engineering, vol. 106, no. 2, pp. 165-173, 1984.

[41] A. Eberhardt, L. Keer and V. Vithoontien, "An analytical model of joint contact," Journal of Biomechanical Engineering, vol. 112, no. 4, pp. 407-413, 1990.

[42] A. Mak, W. Lai and V. Mow, "Biphasic indentation of articular cartilage - I. Theoretical analysis," Journal of Biomechanics, vol. 20, no. 7, pp. 703- 
714, 1987.

[43] S. Woo, S. Abramowitch, R. Kilger and R. Liang, "Biomechanics of knee ligaments: injury, healing, and repairt," Journal of Biomechanics, vol. 39, pp. 1-20, 2006.

[44] D. Bartel, D. Davy and T. Keaveny, Orthopaedic Biomechanics: Mechanics and Design in Musculoskeletal Systems, Upper Saddle River, NJ: Pearson Education, Inc., 2006.

[45] D. Butler, M. Kay and D. Stouffer, "Comparison of material properties in fascicle-bone units from human patellar tendon and knee ligaments," Journal of Biomechanics, vol. 19, no. 6, pp. 425-432, 1986.

[46] T. Haut-Donahue, M. Hull, M. Rashid and C. Jacobs, "How the stiffness of meniscal attachments and meniscal material properties affect tibiofemoral contact pressure computed using a validated finite element model of the human knee joint," Journal of Biomechanics, vol. 36, no. 1, pp. 19-34, 2003.

[47] H. Forster and J. Fisher, "The influence of loading time and lubricant on the friction of articular cartilage," Journal of Engineering in Medicine, vol. 210, no. 2, pp. 109-199, 1996.

[48] V. Mow and G. Ateshian, "Lubrication and wear of diarthrodial joints," in Basic Orthopaedic Biomechanics, Philadelphia, Lippincott-Raven Press, 1997, 
pp. 275-315.

[49] S. Delp, F. Anderson, A. Arnold, P. Loan, A. Habib, C. John, E. Guendelman and D. Thelen, "OpenSim: open-source software to create and analyze dynamic simulations of movement," IEEE Transactions on Biomedical Engineering, vol. 54, no. 11, pp. 1940-1950, 2007.

[50] C. Au and J. Dunne, "OpenSim Documentation: Gait 2392 and 2354," 9 August 2013. [Online]. Available: http://simtkconfluence.stanford.edu:8080/display/OpenSim/Gait+2392+and+2354+ Models. [Accessed November 2013].

[51] M. Liu, F. Anderson, M. Schwartz and S. Delp, "Muscle contributions to support and progression over a range of walking speeds," Journal of Biomechanics, vol. 41, no. 15, pp. 3243-3252, 2008.

[52] J. Hicks, "OpenSim Documentation: Inverse Dynamics," 14 March 2012. [Online]. $\quad$ Available: $\quad$ http://simtkconfluence.stanford.edu:8080/display/OpenSim/Inverse+Dynamics. [Accessed November 2013].

[53] "OpenSim Documentation: Static Optimization," 9 March 2012. [Online]. Available: http://simtkconfluence.stanford.edu:8080/display/OpenSim/Static+Optimization. [Accessed November 2013]. 
[54] J. Hicks, "OpenSim Documentation: Joint Reactions Analysis," 7 January 2013. [Online]. Available: http://simtkconfluence.stanford.edu:8080/display/OpenSim/Joint+Reactions+Analys is. [Accessed November 2013].

[55] J. Yao, P. Funkenbusch, M. Maloney and A. Lerner, "Sensitivities of medial meniscal motion and deformation to material properties of articular cartilage, meniscus, and meniscal attachments using design of experiments methods," Journal of Biomechanics, vol. 128, pp. 399-408, 2006.

[56] J. Jeffrey, D. Gregory and R. Aspden, "Matrix damage and chondrocyte viability following a single impact load on articular cartilage," Archives of Biochemistry and Biophysics, vol. 322, no. 1, pp. 87-96, 1995.

[57] W. Wilson, C. van Burken, C. van Donkelaar, P. Buma, B. van Rietbergen and R. Huiskes, "Causes of mechanically induced collagen damage in articular cartilage," Journal of Orthopaedic Research, pp. 220-228, 2006.

[58] H. Silyn-Roberts and N. Broom, "Fracture behaviour of cartilage-on-bone in response to repeated imact loading," Connective Tissue Research, vol. 24, no. 2, pp. 143-156, 1990.

[59] T. Quinn, R. Allen, B. Schalet, P. Perumbuli and E. Hunziker, "Matrix and cell injury due to sub-impact loading of adult bovine articular cartilage explants: effects of strain rate and peak stress," Journal of Orthopaedic 
Research, vol. 19, no. 2, pp. 242-249, 2001.

[60] J. Bingham, R. Papannagari, S. Van de Velde, C. Gross, T. Gill, D. Felson, H. Rubash and G. Li, "In vivo cartilage contact deformation in the healthy human tibiofemoral joint," Rheumatology, vol. 47, pp. 1622-1627, 2008.

[61] G. Li, L. DeFrate, S. Park, T. Gill and H. Rubash, "In vivo articular cartilage contact kinematics of the knee," The American Journal of Sports Medicine, vol. 33, no. 1, pp. 102-107, 2005.

[62] G. Yildirim, P. Walker, J. Sussman-Fort, G. Aggarwal, B. White and G. Klein, "The contact locations in the knee during high flexion," The Knee, vol. 14, pp. 379-384, 2007.

[63] F. Liu, M. Kozanek, A. Hosseini, V. d. Velde, G. T. S, H. Rubash and G. Li, "In vivo tibiofemoral cartilage deformation during the stance phase of gait," Journal of Biomechanics, vol. 43, pp. 658-665, 2010.

[64] F. Eckstein, B. Lemberger, C. Gratzke, M. Hudelmaier, C. Glaser, K. Englmeier and M. Reiser, "In vivo cartilage deformation after different types of activity and its dependence on physical training status," Annals of the Rheumatic Diseases, vol. 64, pp. 291-295, 2004.

[65] G. Gold, T. Besier, C. Draper, D. Asakawa, S. Delp and G. Beaupre, "Weightbearing MRI of patellofemoral joint cartilage contact area," Journal of Magnetic Resonance Imaging, vol. 20, pp. 526-530, 2004. 
[66] J. Brechter and C. Powers, "Patellofemoral stress during walking in persons with and without patellofemoral pain," Medicine and Science in Sports and Exercise, pp. 1582-1593, 2002.

[67] M. Adouni, A. Shirazi-Adl and R. Shirazi, "Computational biodynamics of human knee joint in gait: From muscle forces to cartilage stresses," Journal of Biomechanics, 2012.

[68] N. Yang, H. Nayeb-Hashemi, P. Canavan and A. Vaziri, "Effect of frontal plane tiobiofemoral angle on the stress and strain at the knee cartilage during the stance phase of gait," Journal of Orthopaedic Research, vol. 28, no. 12, pp. 1539-1547, 2010.

[69] T. Brown and D. Shaw, "In vitro contact stress distribution on the femoral condyles," Journal of Orthopaedic Research, vol. 2, pp. 190-199, 1984.

[70] J. Ihn, S. Kim and I. Park, "In vitro study of contact area and pressure distribution in the human knee after partial and total meniscectomy," International Orthopaedics, vol. 17, pp. 214-218, 1993.

[71] S. Ostermeier, M. Holst, C. Hurschler, H. Windhagen and C. StukenborgColsman, "Dynamic measurement of patellofemoral kinematic and contact pressure after lateral retinacular release: an in vitro study," Knee Surgery Sports Traumatology Arthroscopy, vol. 15, pp. 547-554, 2007.

[72] T. Besier, C. Draper, G. Gold, G. Beaupre and S. Delp, "Patellofemoral joint 
contact area increases with knee flexion and weight-bearing," Journal of Orthopaedic Research, vol. 23, pp. 345-350, 2005.

[73] G. Li, L. DeFrate, S. Zayontz, S. Park and T. Gill, "The effect of tibiofemoral joint kinematics on patellofemoral contact pressures under simulated muscle loads," Journal of Orthopaedic Research, vol. 22, pp. 801-806, 2004.

[74] C. Herberhold, S. Faber, T. Stammberger, M. Steinlechner, R. Putz, K. Englemeier, M. Reiser and F. Eckstein, "In situ measurement of articular cartilage deformation in intact femoropatellar joints under static loading," Journal of Biomechanics, vol. 32, pp. 1287-1295, 1999.

[75] C. Verlinden, P. Uvin, L. Labey, L. J, J. Bellemans and H. Vandenneucker, "The influence of malrotation of the femoral component in total knee replacement on the mechanics of patellofemoral contact during gait," The Journal of Bone and Joint Surgery, Vols. 92-B, no. 5, pp. 737-742, 2010.

[76] A. Anderson, B. Ellis, S. Maas, C. Peters and J. Weiss, "Validation of finite element predictions of cartilage contact pressure in the human hip joint," Journal of Biomechanical Engineering, vol. 130, 2008.

[77] A. Anderson, B. Ellis, S. Maas and J. Weiss, "Effects of idealized joint geometry on finite element predictions of cartilage contact stresses in 
the hip," Journal of Biomechanics, vol. 43, no. 7, pp. 1351-1357, 2010.

[78] R. Shirazi, A. Shirazi-Adl and M. Hurtig, "Role of cartilage collagen fibrils networks in knee joint biomechanics under compression," Journal of Biomechanics, vol. 41, no. 16, pp. 3340-3348, 2008.

[79] R. Shirazi and A. Shirazi-Adl, "Analysis of partial meniscectomy and ACL reconstruction in knee joint biomechanics under a combined loading," Clinical Biomechanics, vol. 24, pp. 755-761, 2009.

[80] M. Mononen, M. Mikkola, P. Julkunen, R. Ojala, M. Nieminen, J. Jurvelin and R. Korhonen, "Effect of superficial collagen patterns and fibrillation of femoral articular cartilage on knee joint mechanics - a 3D finite element analysis," Journal of Biomechanics, 2011.

[81] E. Pena, B. Calvo, M. Martinez and M. Doblare, "Effect of the size and location of osteochondral defects in degenerative arthritis. A finite element simulation," Computers in Biology and Medicine, vol. 39, no. 9, pp. 376387, 2007.

[82] G. Papaioannou, C. Demetropoulos and Y. King, "Predicting the effects of knee focal articular surface injury with a patient-specific finite element model," The Knee, vol. 17, no. 1, pp. 61-68, 2010.

[83] F. Blanco, R. Guitian, E. Vazquez-Martul, F. de Toro and F. Galdo, "Osteoarthritis chndrocytes die by apoptosis," Arthritis and Rheumatism, 
vol. 41, no. 2, pp. 284-289, 1998.

[84] C. Thomas, C. Fuller, C. Whittles and M. Sharif, "Chodrocyte death by apoptosis is associated with cartilage matrix degradation," Osteoarthritis and Cartilage, vol. 15, no. 1, pp. 27-34, 2007.

[85] C. Chen, M. Bhargava, P. Lin and P. Torzilli, "Time, stress, and location dependent chondrocyte death and collagen damage in cyclically loaded articular cartilage," Journal of Orthopaedic Research, vol. 21, no. 5, pp. 888-898, 2003.

[86] B. Ewers, D. Dvoracek-Driksna, M. Orth and R. Haut, "The extent of matrix damage and chondrocyte death in mechanically traumatized articular cartilage explants depends on rate of loading," Journal of Orthopaedic Research, vol. 19, pp. 779-784, 2001.

[87] R. Repo and J. Finlay, "Survival of articular cartilage after controlled impact," Journal of Bone and Joint Surgery, vol. 59, no. 8, pp. 1068-1076, 1977.

[88] B. Beecher, J. Martin, D. Pedersen, A. Heiner and J. Buckwalter, "Antioxidants block cyclic loading induced chondrocyte death," The lowa Orthopaedic Journal, vol. 27, pp. 1-8, 2007.

[89] S. Hashimoto, T. Nishiyama, S. Hayashi, T. Fujishiro, K. Takebe, N. Kanzaki, R. Kuroda and M. Kurosaka, "Role of p53 in human chondrocyte apoptosis in response to shear strain," Arthritis and Rheumatism, vol. 
60, no. 8, pp. 2340-2349, 2009.

[90] G. Ateshian, L. Soslowsky and V. Mow, "Quantitation of articular surface topography and cartilage thickness in knee joints using stereophotogrammetry," Journal of Biomechanics, vol. 24, no. 8, pp. 761-776, 1991.

[91] T. Guess, H. Liu, S. Bhashyam and G. Thiagarajan, "A multibody knee model with discrete cartilage prediction of tibio-femoral contact mechanics," Computer Methods in Biomechanics and Biomedical Engineering, 2011.

[92] T. Guess, G. Thiagarajan, M. Kia and M. Mishra, "A subject specific multibody model of the knee with menisci," Medical Engineering \& Physics, vol. 32, no. 5, pp. 505-515, 2010.

[93] Y. Dhaher, T. Kwon and M. Barry, "The effect of connective tissue material uncertainties on knee joint mechanics under isolated loading conditions," Journal of Biomechanics, vol. 43, no. 16, pp. 3118-3125, 2010.

[94] L. Li and K. Gu, "Reconsideration on the use of elastic models to predict the instantaneous load response of the knee joint," Journal of Engineering, vol. 225, no. 9, pp. 888-896, 2011.

[95] A. Davol, M. Bingham, R. Sah and S. Klisch, "A nonlinear finite element model of cartilage growth," Biomechanics and Modeling in Mechanobiology, vol. 7, pp. 295-307, 2008. 
[96] T. Ficklin, A. Davol and S. Klisch, "Simulating the growth of articular cartilage explants in a permeation bioreactor to aid in experimental protocol design," Journal of Biomechnical Engineering, vol. 131, pp. 1-11, 2009.

[97] M. Stender, C. Raub, K. Yamauchi, R. Shirazi, P. Vena, R. Sah, S. Hazelwood and S. Klisch, "Integrating qPLM and biomechanical test data with an anisotropic fiber distibution model and predictions of TGF-beta 1 and IGF-1 regulation of articular cartilage fiber modulus," Biomechanics and Modeling in Mechanobiology, 2012.

[98] G. Thomas, A. Asanbaeva, P. Vena, R. Sah and S. Klisch, "A constituentbased nonlinear viscoelastic model for articular cartilage and analysis of tissue remodeling due to altered glycosaminoglycan-collagen interactions," Journal of Biomechanical Engineering, vol. 131, p. 101002 , 2009.

[99] B. Kurz, M. Jin, P. Patwari, D. Cheng, M. Lark and A. Grodzinsky, "Biosynthetic response and mechanical properties of articular cartilage after injurious compression," Journal of Orthopaedic Research, vol. 19, no. 6, pp. 1140-1146, 2001.

[100] V. Morel and T. Quinn, "Cartilage injury by ramp compression near the gel diffusion rate," Journal of Orthopaedic Research, vol. 22, pp. 145-151, 2004. 
[101] W. Curl, J. Krome, E. Gordon, J. Rushing, B. Smith and G. Poehling, "Cartilage injuries: a review of 31,516 arthroscopies," Arthroscopy: The Journal of Arthroscopic \& Related Surgery, vol. 13, no. 4, pp. 456-460, 1997.

[102] M. Ding, C. Danielsen and I. Hvid, "Bone density does not reflect mechanical properties in early-stage arthrosis," Acta Orthop Scand, vol. 72, no. 2, pp. 181-185, 2001.

[103] I. Hvid and S. Hansen, "Trabecular bone strength patterns at the proximal tibial epiphysis," Journal of Orthopaedic Research, vol. 3, no. 4, pp. 464-472, 1985.

[104] S. Faber, F. Eckstein, S. Lukasz, R. Muhlbauer, J. Hohe, K. H. Englmeier and M. Reiser, "Gender differences in knee joint cartilage thickness, volume and articular surface areas: assessment with quantitative threedimensional MR imaging," Skeletal Radiology, vol. 30, pp. 144-150, 2001.

[105] H. Sittek, F. Eckstein, A. Gavazzeni, S. Milz, B. Kiefer, E. Schulte and M. Reiser, "Assessment of normal patellar cartilage volume and thickness using MRI: an analysis of currently available pulse sequences," Skeletal Radiology, vol. 55, pp. 55-62, 1996.

[106] K. M. Varadarajan, T. J. Gill, A. A. Freiberg, H. E. Rubash and L. Guoan, "Patellar tendon orientation and patellar tracking in male and female 
knees," Journal of Orthpaedic Research, vol. 28, pp. 322-328, 2010.

[107] C. Belvedere, A. Ensini, A. Feliciangeli, F. Cenni, V. D'Angeli, S. Giannini and A. Leardini, "Geometrical changes of knee ligaments and patellar tendon during passive flexion," Journal of Biomechanics, vol. 45, pp. 18861892, 2012. 


\title{
APPENDIX A
}

\section{UVARM SUBROUTINE FOR CONVERTING LOGARITHMIC STRAIN TO}

\section{EQUIVALENT GREEN-LAGRANGIAN STRAIN}

\author{
SUBROUTINE UVARM (UVAR, DIRECT, T, TIME, DTIME, CMNAME, ORNAME, \\ 1 \\ NUVARM, NOEL, NPT, NLAYER, NSPT, KSTEP, KINC, \\ 2 \\ NDI, NSHR, COORD, JMAC, JMATYP, MATLAYO, LACCELG) \\ C \\ C \\ INCLUDE 'ABA_PARAM.INC ' \\ CHARACTER $* 80$ CMNAME, ORNAME \\ DIMENSION UVAR (6), TIME (2), DIRECT $(3,3), \mathrm{T}(3,3), \operatorname{COORD}(*)$, \\ $\$ \quad \operatorname{JMAC}(*), \operatorname{JMATYP}(*)$ \\ C USER DEFINED DIMENSION STATEMENTS \\ CHARACTER * 3 FLGRAY (15) \\ DIMENSION ARRAY (15), JARRAY (15) \\ C DIMENSION LE1 (1), LE2 (1), LE3 (1), LAM1 (1), LAM2 (1), LAM3 (1) \\ C \\ C The dimensions of the variables ARRAY and JARRAY \\ C must be set equal to or greater than 15 \\ C \\ CALL GETVRM( 'LEP', ARRAY, JARRAY, FLGRAY, JRCD, \\ \$ JMAC, JMATYP, MATLAYO, LACCFLG) \\ C \\ C Calculate principal stretches from LE, then calculate lagrangian \\ C strains from principal stretches. Also calculate max shear strain \\ C \\ $\operatorname{UVAR}(1)=.5 *((2.718282 * * \operatorname{ARRAY}(1)) * * 2-1)$ \\ $\operatorname{UVAR}(2)=.5 *((2.718282 * * \operatorname{ARRAY}(2)) * * 2-1)$ \\ $\operatorname{UVAR}(3)=.5 *((2.718282 * * \operatorname{ARRAY}(3)) * * 2-1)$ \\ $\operatorname{UVAR}(4)=(\operatorname{UVAR}(3)-\operatorname{UVAR}(1)) / 2$ \\ C \\ RETURN \\ END
}

